\title{
Chronic fractalkine administration improves glucose tolerance and pancreatic endocrine function
}

\author{
Matthew Riopel, ${ }^{1}$ Jong Bae Seo, ${ }^{1,2}$ Gautam K. Bandyopadhyay, ${ }^{1}$ Pingping Li, ${ }^{1,3}$ Joshua Wollam, ${ }^{1}$ Heekyung Chung, ${ }^{1}$ \\ Seung-Ryoung Jung, ${ }^{2}$ Anne Murphy, ${ }^{4}$ Maria Wilson, ${ }^{5}$ Ron de Jong, ${ }^{5}$ Sanjay Patel, ${ }^{5}$ Deepika Balakrishna, ${ }^{5}$ James Bilakovics, ${ }^{5}$ \\ Andrea Fanjul, ${ }^{5}$ Artur Plonowski, ${ }^{5}$ Duk-Su Koh, ${ }^{2}$ Christopher J. Larson, ${ }^{5,6}$ Jerrold M. Olefsky, ${ }^{1}$ and Yun Sok Lee ${ }^{1,7}$

\begin{abstract}
'Department of Medicine, Division of Endocrinology and Metabolism, UCSD, La Jolla, California, USA. 'Department of Physiology and Biophysics, University of Washington, Seattle, Washington, USA. ${ }^{3}$ State Key Laboratory of Bioactive Substance and Function of Natural Medicines, Institute of Materia Medica, Peking Union Medical College and Chinese Academy of Medical Sciences, Beijing, China. ${ }^{4}$ Department of Pharmacology, UCSD, La Jolla, California, USA. ${ }^{5}$ Cardiovascular and Metabolic Diseases Drug Discovery Unit, Takeda Pharmaceuticals, San Diego, California, USA. ${ }^{6}$ Sanford Burnham Prebys Medical Discovery Institute, La Jolla, California, USA. ${ }^{7}$ Graduate School of Medical Science and Engineering, Korea Advanced Institute of Science and Technology, Daejeon, South Korea.
\end{abstract}

\begin{abstract}
We have previously reported that the fractalkine (FKN)/CX3CR1 system represents a novel regulatory mechanism for insulin secretion and $\beta$ cell function. Here, we demonstrate that chronic administration of a long-acting form of FKN, FKN-Fc, can exert durable effects to improve glucose tolerance with increased glucose-stimulated insulin secretion and decreased $\beta$ cell apoptosis in obese rodent models. Unexpectedly, chronic FKN-Fc administration also led to decreased $\alpha$ cell glucagon secretion. In islet cells, FKN inhibited ATP-sensitive potassium channel conductance by an ERK-dependent mechanism, which triggered $\beta$ cell action potential (AP) firing and decreased $\alpha$ cell AP amplitude. This results in increased glucose-stimulated insulin secretion and decreased glucagon secretion. Beyond its islet effects, FKN-Fc also exerted peripheral effects to enhance hepatic insulin sensitivity due to inhibition of glucagon action. In hepatocytes, FKN treatment reduced glucagon-stimulated cAMP production and CREB phosphorylation in a pertussis toxin-sensitive manner. Together, these results raise the possibility of use of FKN-based therapy to improve type 2 diabetes by increasing both insulin secretion and insulin sensitivity.
\end{abstract}

\section{Introduction}

In type 2 diabetes mellitus (T2DM), progression to the full hyperglycemic state is associated with 2 major pathophysiological defects: insulin resistance and $\beta$ cell dysfunction (1-3). While the relative contribution and temporal appearance of these events vary across different patients and populations, these 2 abnormalities usually exist concomitantly in the majority of patients (4). Therefore, an ideal antidiabetic therapeutic would involve strategies to enhance both insulin sensitivity and $\beta$ cell function.

One component of insulin's action to suppress postprandial hyperglycemia is to counteract the effects of glucagon $(5,6)$. In T2DM, insulin resistance potentiates $\alpha$ cell glucagon secretion and hepatic glucagon action, which stimulates hepatic glucose production $(7,8)$. Recently, it has been shown that inhibition of glucagon action using glucagon receptor-antagonizing antibodies normalizes blood glucose levels in streptozotocin-treated insulin-deficient mice (9). Glucose-lowering effects of glucagon antagonism have also been demonstrated in nonhuman primates and humans (1013). Moreover, hepatocyte-specific deletion of the glucagon recep-

Authorship note: MR and JBS are co-first authors.

Conflict of interest: $\mathrm{HC}$ is employed by Samumed LLC. MW, RDJ, SP, DB, JB, AF, and AP are employed by Takeda California Inc. YSL and JMO have received research funding from Takeda California Inc. FKN and CX3CR1 molecules and related methods of use reported in this study are covered in patent 9764001 invented by JMO and YSL.

Submitted: March 31, 2017; Accepted: January 18, 2018.

Reference information: J Clin Invest. 2018;128(4):1458-1470.

https://doi.org/10.1172/JCI94330. tor improves glucose tolerance with improved insulin sensitivity (14), suggesting that inhibition of glucagon secretion and/or action is beneficial for improving glucose tolerance and insulin sensitivity.

An impaired insulin response to glucose has long been documented in T2DM subjects (15-19), and evidence indicates that $\beta$ cell dysfunction involves a decline in both $\beta$ cell responsiveness to insulin secretagogues and overall $\beta$ cell mass $(4,20)$. Ex vivo glucosestimulated insulin secretion (GSIS) is diminished in primary islets from T2DM patients compared with normal subjects (20), indicating that there is an islet-autonomous defect in GSIS in T2DM.

Secretion of insulin and glucagon is tightly regulated by blood glucose concentration, and, at the molecular level, the response to glucose is largely mediated through a common mechanism involving ATP-sensitive potassium $\left(\mathrm{K}_{\mathrm{ATP}}\right)$ channel regulation (21). The postprandial rise in blood glucose increases the ATP/ADP ratio, leading to inhibition of $\mathrm{K}_{\text {ATP }}$ channel activity and plasma membrane depolarization in $\alpha$ and $\beta$ cells. In $\beta$ cells, this leads to action potential (AP) firing and insulin secretion (21). On the other hand, in $\alpha$ cells, basal membrane potential is already depolarized with spontaneous AP firing at low glucose levels, and further depolarization of membrane potential by glucose-dependent inhibition of $\mathrm{K}_{\text {ATP }}$ channels results in decreased AP amplitude and decreased glucagon secretion. Recently, it has been suggested that a slight increase in basal $\mathrm{K}_{\text {ATP }}$ channel conductance or incomplete inhibition of $\mathrm{K}_{\mathrm{ATP}}$ channel activity by glucose may be responsible for the decreased glucose response in $\alpha$ and $\beta$ cells in T2DM $(22,23)$.

Circulating fractalkine (FKN; also called CX3CL1) is a peptide released into the bloodstream by proteolytic cleavage of the 
CX3CL1 extracellular domain and is readily detected in mouse and human blood $(24,25)$. Cellular FKN effects are largely mediated through its cognate receptor CX3CR1 (26). Recently, we reported that CX3CR1-deficient mice exhibit glucose intolerance mainly due to $\beta$ cell dysfunction, while FKN treatment improves glucose tolerance and increases insulin secretion in vivo (27). FKN also potentiates GSIS in vitro in both mouse and human islets. Additionally, it has been shown that FKN treatment of human islets decreases glucagon release and protects against TNF- $\alpha$-induced decreased GSIS (28). In this study, we used a long-acting FKN-Fc fusion protein to conduct chronic treatment studies in obese mice. The results show that FKN-Fc administration leads to improved glucose tolerance, increased insulin secretion, and enhanced hepatic insulin sensitivity. These beneficial effects are mediated by distinct mechanisms in $\beta$ cells, $\alpha$ cells, and hepatocytes.

\section{Results}

An FKN-Fc fusion protein exerts durable effects to enhance insulin secretion and improve glucose tolerance. We previously reported that CX3CR1 (FKN receptor) deficiency causes $\beta$ cell dysfunction and glucose intolerance. Furthermore, acute administration of soluble FKN increases insulin secretion and improves glucose tolerance in lean chow-fed WT mice (27). These results suggested that FKN may have translational importance for antidiabetes therapy, raising the question of whether chronic FKN administration can exert durable beneficial effects to improve insulin secretion and glucose tolerance in obese/diabetic mice. Native soluble FKN is not adequate to test this idea, since it is rapidly cleared with a half-life of approximately 30 minutes (data not shown). To overcome this problem, we first generated a long-acting form of soluble FKN by fusing the chemokine domain (76 amino acids) of native FKN to a mouse IgG Fc fragment. This chimeric FKN-Fc fusion protein displayed a significantly increased in vivo half-life ( $\sim 6$ hours) in both normal chow diet (NCD) and high-fat diet (HFD) mice (data not shown). As seen in Figure 1, A-C, acute administration of FKN-Fc improved glucose tolerance and increased plasma insulin levels in both NCD and HFD mice. In NCD mice, these beneficial effects of FKN-Fc persisted up to 2 days at the dose $10 \mathrm{mg} / \mathrm{kg}$ (Supplemental Figure 1; supplemental material available online with this article; https://oi.org/10.1172/JCI94330DS1), and, upon repeated treatment at day 5 , there was continued improvement in glucose tolerance (Figure 1B), indicating no decreased FKN sensitivity with repeated dosing. In HFD mice, the effect of FKN persisted for 2 days at a dose of $30 \mathrm{mg} / \mathrm{kg}$ (Figure 1C), a dose at which the effect persisted for 5 days in NCD mice (data not shown). Furthermore, plasma glucagon levels were decreased by acute FKN-Fc administration in both NCD and HFD mice (Figure 1D). Together, these data suggest that acute administration of FKN-Fc increases plasma insulin levels, decreases plasma glucagon levels, and improves glucose tolerance in both NCD and HFD mice.

We next tested the effects of chronic administration of FKNFc in HFD obese/diabetic mice. WT B6 mice were fed HFD for 10 weeks and then treated with FKN-Fc $(30 \mathrm{mg} / \mathrm{kg})$ every other day for an additional 8 weeks. During the 8 weeks of treatment, the mice were maintained on HFD. As seen in Figure 1, E and F, chronic FKN-Fc administration did not change body weight or food intake. Chronic FKN-Fc administration significantly improved glucose tolerance in HFD WT mice (Figure 1G), but not in HFD CX3CR1-KO mice (Figure 1H), showing that these beneficial effects of FKN-Fc are CX3CR1-dependent. Interestingly, chronic FKN-Fc administration decreased fasting plasma insulin level (Figure 1I), similarly to what has been reported in chronic GLP-1 analog-treated animals (29).

Chronic FKN-Fc treatment enhances insulin secretion and decreases $\beta$ cell apoptosis in obese mice. $\beta$ Cell dysfunction in T2DM is characterized by reduced GSIS activity and decreased $\beta$ cell mass due to apoptosis (4). Interestingly, in primary mouse islets, FKN-Fc stimulated GSIS and inhibited the effect of palmitate treatment to cause apoptosis (Figure 2, A and B). On the other hand, insulin secretion was not affected by FKN-Fc treatment in low-glucose conditions (Supplemental Figure 2A). To assess this concept in isolated islets, we first measured GSIS in the islets isolated from vehicle- and FKN$\mathrm{Fc}$-treated mice. As seen in Figure 2C and Supplemental Figure 2, $\mathrm{B}$ and $\mathrm{C}$, chronic FKN-Fc administration increased GSIS activity in the islets of HFD mice. In addition, the HFD-induced decrease in the expression of genes involved in $\beta$ cell differentiation and function, such as Pdx1, Neurod, Glut2, Mafa, and Cx36, was prevented by FKN-Fc administration (Figure 2D and Supplemental Figure 2D). Next, we tested changes in $\beta$ cell apoptosis and found that caspase-3/7 activity was significantly diminished in islets by FKNFc administration to HFD mice (Figure 2E).

To test this idea in the in vivo setting, we quantified apoptotic cell number in FKN-Fc-treated mice. In HFD mice, the number of apoptotic $\beta$ cells (active caspase-3- and insulin-double-positive cells) was marginal (only $1-2$ cells per islet) (data not shown), making it unfeasible to detect an FKN-Fc-induced decrease in apoptosis using immunohistochemistry. To overcome this problem, we examined other models of obesity and found that 15-week-old $o b / o b$ mice exhibited a higher number $(\sim 4 \%)$ of apoptotic islet $\beta$ cells (Figure 2F). Seven weeks of chronic FKN-Fc administration significantly improved glucose tolerance (Supplemental Figure 2E) and markedly decreased the number of apoptotic $\beta$ cells in the $o b / o b$ mouse islets (Figure $2 \mathrm{~F}$ ). Consistent with this, caspase-3/7 activity (Supplemental Figure $2 \mathrm{~F}$ ) and the expression of genes involved in $\beta$ cell apoptosis, such as Txnip, $p 21$, and Icer, were decreased by FKN-Fc administration (Figure $2 \mathrm{G}$ ), while the expression of genes involved in $\beta$ cell differentiation was increased (Supplemental Figure $2 \mathrm{G}$ ). In addition, overall $\beta$ cell mass was significantly increased (Figure $2 \mathrm{H}$ ), without changes in islet number per pancreatic area in HFD WT mice (Figure 2I).

Chronic FKN-Fc administration inhibits hepatic glucose production and improves hepatic insulin sensitivity. Since fasting plasma insulin was markedly decreased without change in fasting glucose level by chronic FKN-Fc administration in HFD mice (Figure 1I), we questioned whether the improved glucose tolerance is associated with enhanced insulin sensitivity. To assess this, we performed insulin tolerance tests. As seen in Figure 3A, chronic FKNFc administration significantly improved insulin tolerance in HFD WT mice at 90 and 120 minutes. To quantitate systemic insulin sensitivity and assess tissue-specific effects, we performed hyperinsulinemic-euglycemic clamp studies in these mice. As seen in Figure 3, B-D, the glucose infusion rate was increased $56 \%$ by chronic FKN-Fc administration, and this systemic effect was due to increased hepatic insulin sensitivity (Figure $3 \mathrm{C}$ ) with no change 

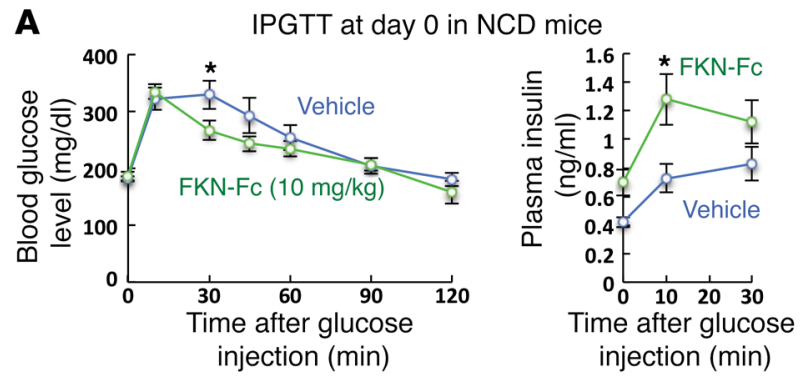

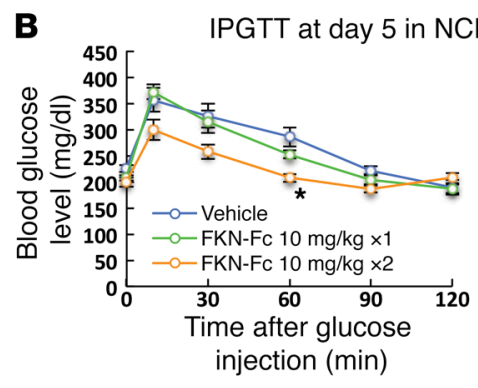

D

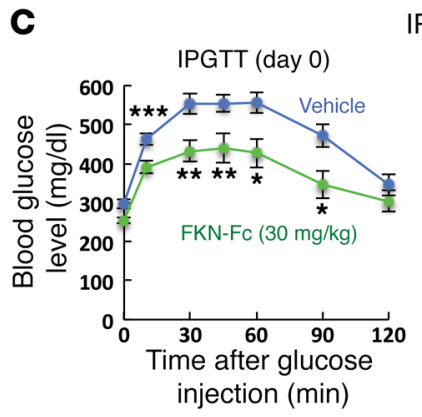

IPGTT in HFD mice

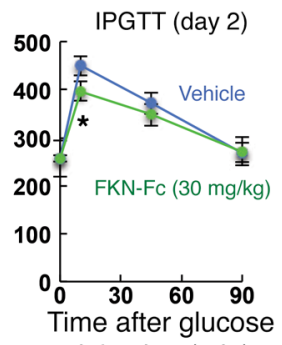

injection ( $\mathrm{min})$

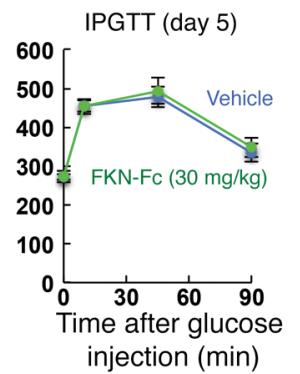

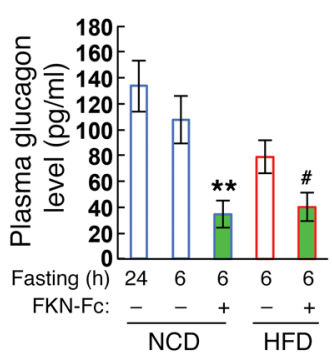

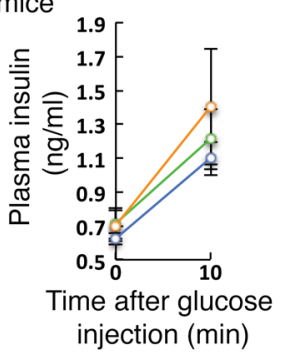

E

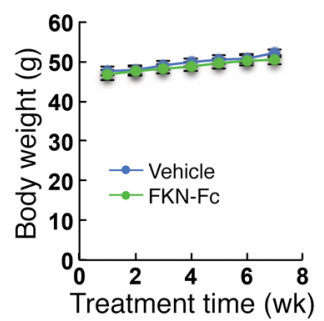

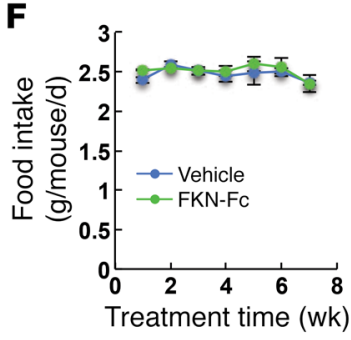

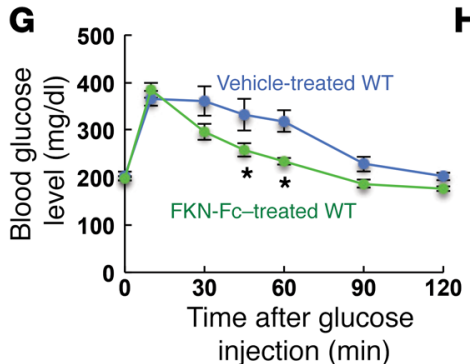

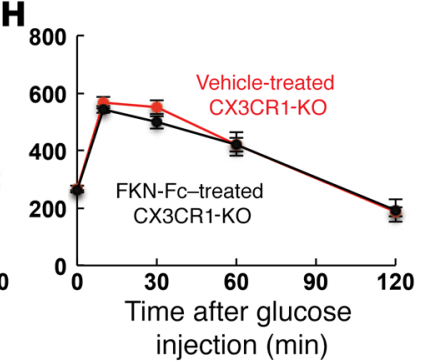

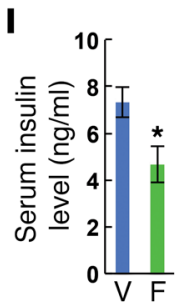

Figure 1. Chronic administration of a chimeric FKN-Fc fusion protein exerts durable effects to improve glucose tolerance with increased insulin and decreased glucagon secretion in HFD/obese mice. (A) Intraperitoneal glucose tolerance tests (IPGTTs) in NCD WT mice at day $0 . n=8$ for both groups. (B) CTTs in NCD WT mice at day 5. A single injection of $10 \mathrm{mg} / \mathrm{kg}$ FKN-Fc or vehicle was given to NCD WT mice at day 0 and, at day 5 , glucose tolerance (left) and plasma insulin levels (right) were measured with (FKN-Fc $10 \mathrm{mg} / \mathrm{kg} \times 2$ ) or without (vehicle and FKN-Fc $10 \mathrm{mg} / \mathrm{kg} \times 1)$ acute FKN-Fc administration. $n=8$ for each group. (C) GTTs were performed in HFD WT mice at 0 (left), 2 (middle) or 5 (right panel) days after a single FKN-Fc injection (day 0 ). $n=8$ for both groups. (D) Fasting plasma glucagon levels in NCD and HFD (16 week) WT mice before and 10 min after $30 \mathrm{mg} / \mathrm{kg} \mathrm{FKN-Fc} \mathrm{injection.} \mathrm{Mean} \pm$ SEM. $n=8$ for each group. (E-I) Effects of chronic FKN-Fc administration in HFD mice. Body weight (E; $n=20$ WT mice), daily food intake (F; $n=5$ WT mice), glucose tolerance (G, $n=8$ WT mice; $\mathbf{H}, n=8$ CX3CR1 KO mice) and serum insulin (I, $n=8$ WT mice) levels were measured during or after 8 weeks of FKN-Fc treatment. V, vehicle; F, FKN-Fc. For statistical analysis, 2-way ANOVA with post-hoc $t$ tests between the individual groups (A-C and E-H), 1-way ANOVA (D) or 2-tailed unpaired $t$ test (I) was performed. In all panels, values are mean \pm SEM and the symbols indicate statistical analysis: ${ }^{*} P<0.05$;

${ }^{* *} P<0.01 ;{ }^{* *} P<0.001$ versus vehicle controls or lane $1 ;{ }^{*} P<0.05$ versus lane 4 . See also Supplemental Figure 1.

in basal or insulin-stimulated glucose disposal rates (Figure 3D). Moreover, liver mass, triglyceride, nonesterified fatty acid content, and histologic indications of steatosis were all significantly reduced by chronic FKN-Fc treatment in HFD WT mice and $o b / o b$ mice (Supplemental Figure 3).

Mechanism of FKN effects on hepatocytes. To determine whether this in vivo effect on hepatic insulin resistance is hepatocyteautonomous, or through an indirect mechanism, we incubated mouse primary hepatocytes isolated from normal mice with glucagon, insulin, and/or FKN and measured glucose production from these cells. As seen in Figure 3E, FKN markedly reduced glucagon-stimulated glucose production from ${ }^{14} \mathrm{C}$-labeled pyruvate. Concomitant with this, FKN treatment reduced glucagonstimulated cAMP levels (Figure 3F) and cAMP responsive elementbinding protein (CREB) phosphorylation (Figure 3G), comparable to the effect of insulin. Mechanistically, FKN-dependent suppression of hepatic glucose production was blocked by pertussis toxin treatment (Figure 3H), but not by inhibition of MEK (Supplemental Figure $3 G$ ), indicating that FKN can suppress hepatic glucagon action by a $G_{\mathrm{ai}}$-dependent mechanism. Next, we tested insulinresistant HFD mouse hepatocytes. In these cells, FKN treatment caused a trend toward decreased glucagon-stimulated glucose production (Figure 3I), although this did not reach statistical significance. Notably, FKN potentiated insulin-dependent suppression of glucagon-stimulated glucose production and cAMP levels (Figure 3, I and J). Taken together, these results suggest that FKN activates the $G_{\alpha i}$ pathway in hepatocytes and can enhance hepatic insulin action by antagonizing glucagon.

Mechanism of FKN effects on $\beta$ cells. Our studies show that FKN stimulates insulin secretion in vivo in mice and in vitro in isolated 

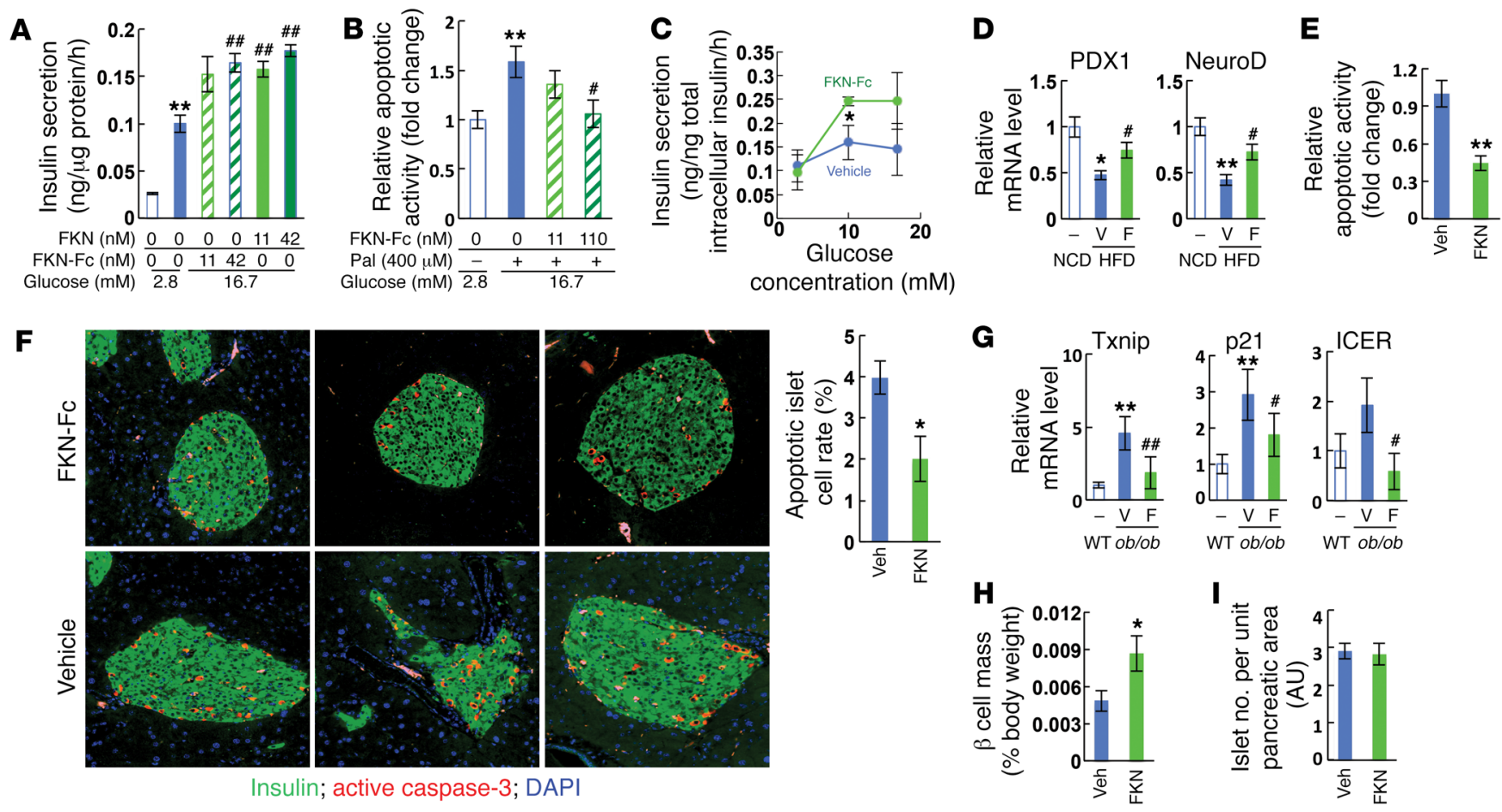

Figure 2. Chronic FKN-Fc administration enhances GSIS and decreases apoptosis in the islets of obese mice. (A) Static GSIS in primary mouse islets. (B) Relative apoptotic activity in primary mouse islet cells. Pal, palmitate. (C-E) Chronic FKN-Fc administration improves CSIS and decreases apoptosis in islets of HFD WT mice. 10 week HFD mice were treated with vehicle or FKN-Fc for an additional 8 weeks. Islets were isolated and similar sized islets were picked under the microscope and subjected to in vitro GSIS (C), quantitative RT-PCR (Q-PCR) (D) and caspase-3/7 activity assays (E). (F-C) Chronic FKN-Fc administration decreases $\beta$ cell apoptosis in ob/ob mice. 8 week-old ob/ob mice were ip injected with vehicle or $30 \mathrm{mg} / \mathrm{kg}$ FKN-Fc every other day for 7 weeks. $\beta$ cell apoptosis and apoptoic gene expression was assessed by immunohistochemistry (IHC) analyses using anti-insulin and anti-active (cleaved) caspase-3 antibodies $(\mathbf{F})$ and Q-PCR (C), respectively. $n=4$. (H and I) Morphometric analyses of HFD mouse islets. 10 week HFD mice were treated with FKN-Fc every other day for 8 weeks. A whole pancreas was harvested from each mouse, weighed and then fixed for IHC analyses. $\beta$ Cell mass (H) and islet number per unit pancreatic area (I) were measured after staining with anti-insulin antibody, as described in Methods. Images are obtained at $\times 20$ magnification. AU, arbitrary unit. For statistical analysis, 2-tailed paired $t$ test $(\mathbf{C}, \mathbf{E}, \mathbf{F}$, and $\mathbf{H})$ or 1-way ANOVA (A, B, D, and $\mathbf{C})$ was performed. In all graph panels, values are mean \pm SEM and the symbols indicate statistical analysis: ${ }^{*} P<0.05$ versus lane $1 ;{ }^{* *} P<0.01$ versus lane 1 ; ${ }^{*} P<0.05$ versus lane 2 ; $\# P<0.01$ versus lane 2 . See also Supplemental Figure 2 .

mouse and human islets through CX3CR1. $\beta$ Cells are electrically excitable by insulin secretagogues, and modulation of cation channels provokes action potential (AP) firing, leading to activation of voltage-dependent $\mathrm{Ca}^{2+}$ channels (VDCCs), increased intracellular calcium ion $\left(\mathrm{Ca}^{2+}\right)$ levels, and $\mathrm{Ca}^{2+}$-dependent insulin exocytosis. Since our earlier studies showed that FKN stimulates GSIS by potentiating glucose-dependent increases in intracellular $\beta$ cell $\mathrm{Ca}^{2+}$ levels (27), we have now conducted a series of electrophysiology studies to examine the molecular mechanisms of this effect. First, we examined whether FKN modulates $\beta$ cell cation channels critical for GSIS, including the $\mathrm{K}_{\text {ATP }}$ channel and/or the VDCC, using patch-clamp techniques. When Min6 cells were incubated in low-glucose $(2 \mathrm{mM})$ medium for 16 hours, resting $\mathrm{K}_{\mathrm{ATP}}$ current density was $25.3 \pm 2.86 \mathrm{pA} / \mathrm{pF}$ in an external solution containing $40 \mathrm{mM} \mathrm{KCl}$. Upon FKN treatment, the $\mathrm{K}_{\text {ATP }}$ channels were rapidly inhibited within 30 seconds in a dose-dependent manner $(81.5 \%$ $\pm 5.07 \%$ and $99.4 \% \pm 0.51 \%$ by 10 and $100 \mathrm{ng} / \mathrm{ml} \mathrm{FKN}$, respectively), and this effect was not reversed during 2 minutes of washout (Figure 4, A and B). Moreover, this inhibitory effect of FKN occurred without changing cellular ATP levels, the ATP/ADP ratio, or the oxygen consumption rate (Figure 4, C and D, and Supplemental Figure $4 \mathrm{C}$ ). The effects of FKN-Fc were prevented by pre- treatment with the MEK inhibitor U0126 or PD98059 (Figure 4, A and $\mathrm{B}$ ), suggesting that FKN inhibits $\mathrm{K}_{\mathrm{ATP}}$ channel through a MEK/ ERK-dependent mechanism independent of changing mitochondrial activity. Consistent with the Min6 cell data, FKN treatment significantly inhibited $\mathrm{K}_{\mathrm{ATP}}$ channel activity in primary $\beta$ cells from WT mice, but not CX3CR1 KO mice (Figure 4, E and F). Furthermore, FKN treatment led to membrane depolarization (from -74 $\mathrm{mV}$ to $-35.8 \mathrm{mV})$ and $\mathrm{AP}$ firing $(2.2 \pm 0.48 \mathrm{~Hz})$ in low-glucose $(2$ $\mathrm{mM})$ conditions in Min6 cells, when measured in a perforated whole-cell configuration (Figure $4 \mathrm{G}$ ), while cellular metabolic flux (e.g., ATP/ADP ratio) was unchanged. Importantly, when administered after a high-glucose challenge, FKN significantly increased $\mathrm{AP}$ firing frequency $(1.04 \pm 0.21 \mathrm{vs} .2 .02 \pm 0.38 \mathrm{~Hz}$ ) (Figure $4 \mathrm{H})$, suggesting that FKN can potentiate glucose-stimulated electrical activity in $\beta$ cells, leading to increased intracellular $\mathrm{Ca}^{2+}$ levels and insulin secretion. On the other hand, FKN treatment was without direct effect on VDCC activity (Figure 4, I and J). These results indicate that FKN inhibits $\mathrm{K}_{\mathrm{ATP}}$ channel activity, leading to membrane depolarization, which secondarily opens the VDCC, causing increased intracellular $\mathrm{Ca}^{2+}$ levels and GSIS.

Mechanism of FKN effects on a cells. Recently, it was reported that FKN treatment can suppress glucagon release in primary human 
A

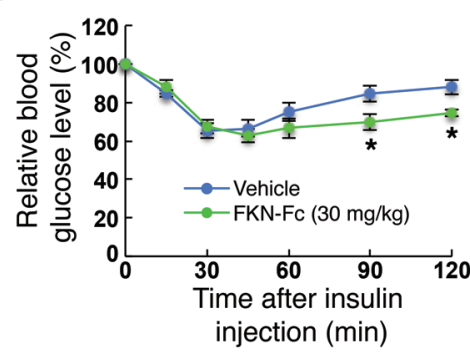

$\square$ Vehicle-treated basal

$\square$ FKN-Fc-treated basal

Vehicle-treated clamped
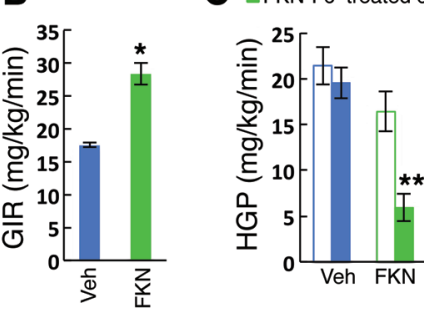

D

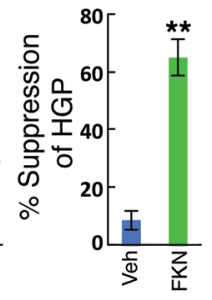

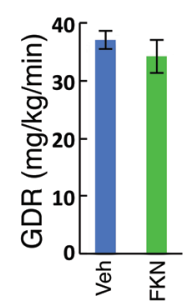

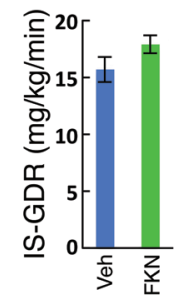

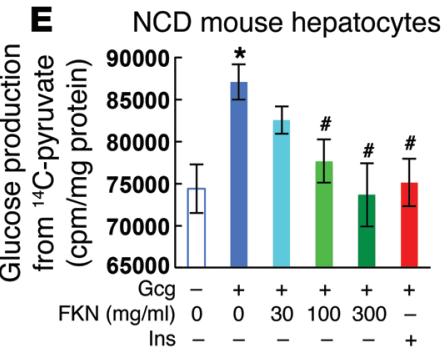

F NCD mouse hepatocytes
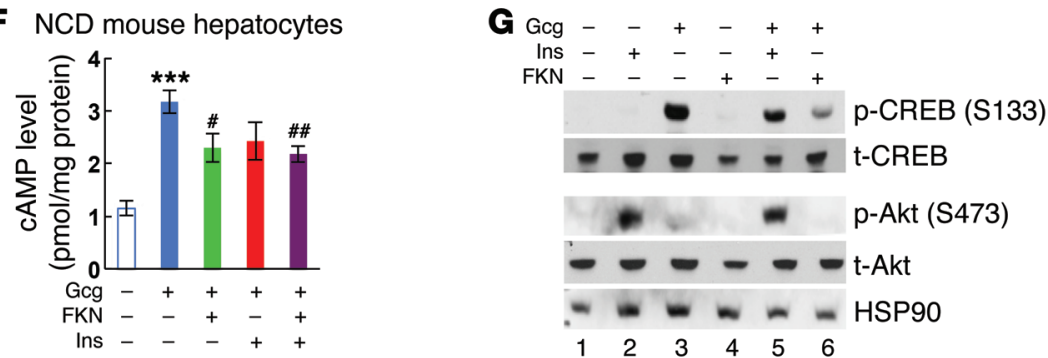

H NCD mouse hepatocytes

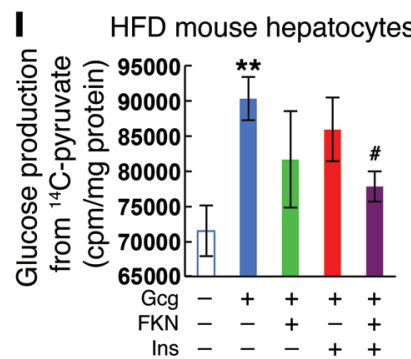

$\mathbf{J}$ HFD mouse hepatocytes

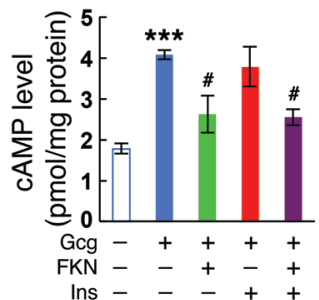

Figure 3. Chronic FKN-Fc administration exerts tissue-specific effects to improve hepatic insulin sensitivity in HFD/obese insulin resistant mice. (A-D) FKN-Fc treatment improves hepatic insulin sensitivity in obese mice. 10 week HFD mice were treated with vehicle or $30 \mathrm{mg} / \mathrm{kg}$ FKN-Fc for 8 weeks and subjected to ITTs (A) or hyperinsulinemic euglycemic clamp studies (B-D). Final FKN-Fc dosing was given 6 hours before the tests, at the start of fasting. Clucose infusion rate (GIR; B), hepatic glucose production (HCP; $\mathbf{C}$ ) and basal (CDR; $\mathbf{D}$ ) and insulin-stimulated glucose disposal rates (IS-CDR; $\mathbf{D})$ were calculated as described previously (53). $n=8$ for ITTs and $n=4$ for clamp studies. In panel A, ITT was performed 2 times in separate cohorts of mice and a representative figure is shown. (E) Cluconeogenic activity in NCD mouse hepatocytes. $n=4$. (F) Intracellular cAMP levels 15 min after hormonal treatment(s) in NCD mouse hepatocytes. $n=4$. (G) CREB and Akt phosphorylation 30 min after hormonal stimulation. (H) Gluconeogenic activity in pertussis toxin (PTX)-treated (30 min pretreatment) NCD mouse hepatocytes. $n=4$. (I) Gluconeogenic activity in HFD mouse hepatocytes. $n=4$. (J) Intracellular cAMP levels in HFD mouse hepatocytes 15 min after hormonal treatment(s). $n=4$. For statistical analysis, ANOVA with post-hoc $t$ tests between the individual groups (A), 2-tailed unpaired $t$ test (B) or 1-way ANOVA (C, E, F, H-J) was performed. In all graph panels, values are mean \pm SEM and the symbols indicate statistical analysis: ${ }^{*} P<0.05$ versus lane $1 ;{ }^{* *} P<0.01$ versus lane $1 ;{ }^{* *} P<0.001$ versus lane $1 ;{ }^{*} P<0.05$ versus lane 2 ; $\# P<0.01$ versus lane 2 . See also Supplemental Figure 3. See complete unedited blots in the supplemental material.

islets (28). Consistent with this, we observed that FKN-Fc administration decreases plasma glucagon levels in mice (Figure 1D). Moreover, in vitro incubation of primary mouse islets with FKN suppressed low-glucose-induced glucagon release, without interfering insulin effects (Figure 5A). Since insulin suppresses $\alpha$ cell glucagon release $(30,31)$, we hypothesized that FKN treatment could decrease glucagon release from $\alpha$ cells, contributing to the improved glucose tolerance (6). Surprisingly, FKN also directly suppressed glucagon release in $\alpha \mathrm{TC} 1$ mouse $\alpha$ cells (Figure 5B), raising the possibility that FKN can act on $\alpha$ cells to inhibit glucagon secretion. Consistent with this idea, immunohistochemistry analysis of mouse islets revealed that there are glucagon-and CX3CR1-double-positive cells in mouse islets (Figure 5C). However, pancreatic endocrine cells expressed relatively low Cx3cr1 mRNA levels, compared with monocytes (data not shown), and using immunohistochemical methods with the CX3CR1 antibody to measure the ratio between CX3CR1 $1^{+}$and CX3CR1- islet cells is not the ideal quantitative approach. Therefore, to obtain more precise insight into CX3CR1 expression in primary $\alpha$ and $\beta$ cells, we performed flow cytometry analyses in dispersed islet cells. As seen in Figure 5D, 97.7\% of glucagon-positive and $97.1 \%$ of insulin-positive cells were CX3CR1 ${ }^{+}$, showing that most of the primary $\alpha$ and $\beta$ cells express CX3CR1.

High glucose levels suppress $\alpha$ cell glucagon release by the same cellular mechanisms whereby glucose stimulates GSIS: inhibition of $\mathrm{K}_{\text {ATP }}$ channel activity. Compared with $\beta$ cells, $\alpha$ cell $\mathrm{K}_{\mathrm{ATP}}$ channel conductance is much less $(1 \%-10 \%)$ in the absence of glucose, and relatively less ATP is required to attenuate whole-cell $\mathrm{K}_{\text {ATP }}$ currents in $\alpha$ cells than in $\beta$ cells (21). Therefore, unlike in $\beta$ cells, the basal membrane potential in $\alpha$ cells is already depolarized (about -40 $\mathrm{mV}$ ) even at relatively low levels of intracellular ATP, as seen in 
A

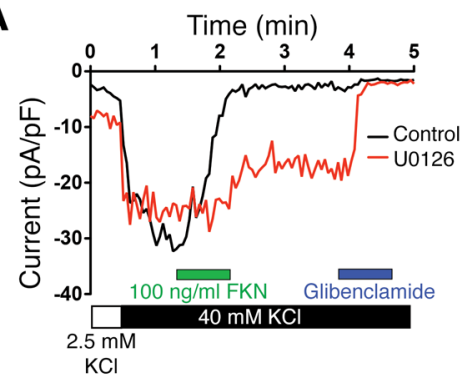

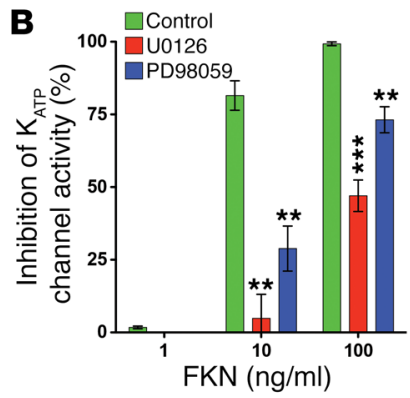

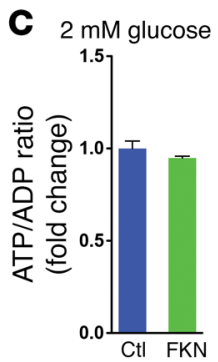

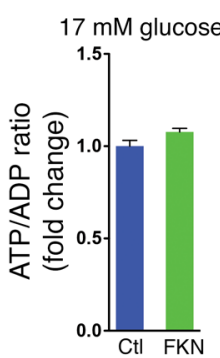

D

$\multimap-2.8 \mathrm{mM}$ glucose + vehicle $\multimap-2.8 \mathrm{mM}$ glucose $+\mathrm{FKN}$

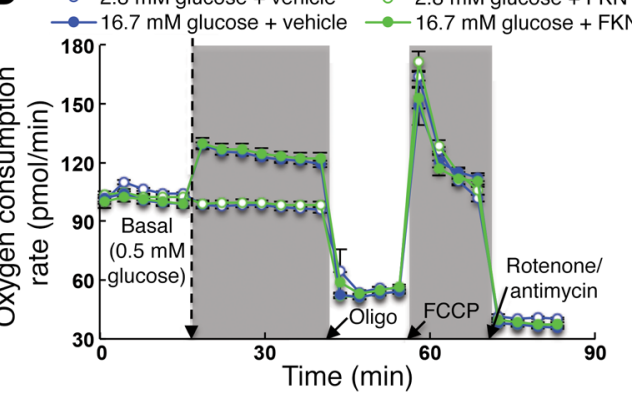

E

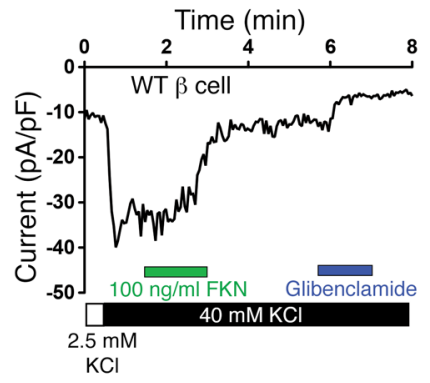

$\mathbf{F}$

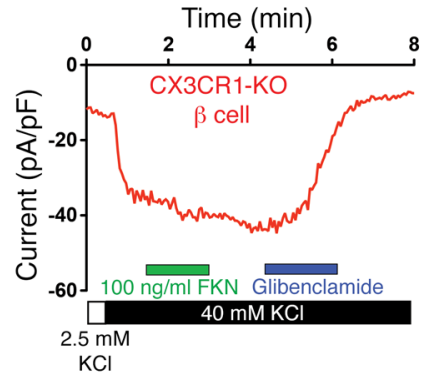

G

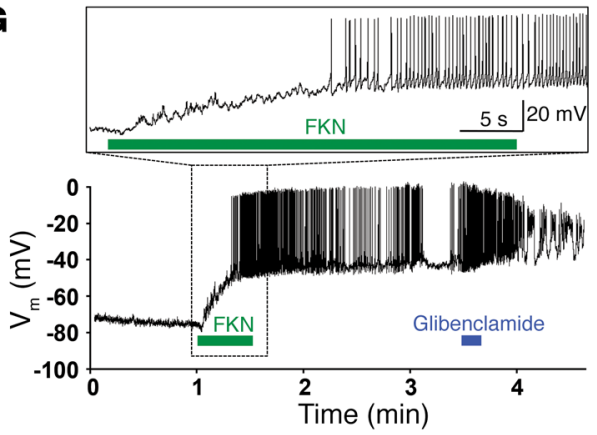

H

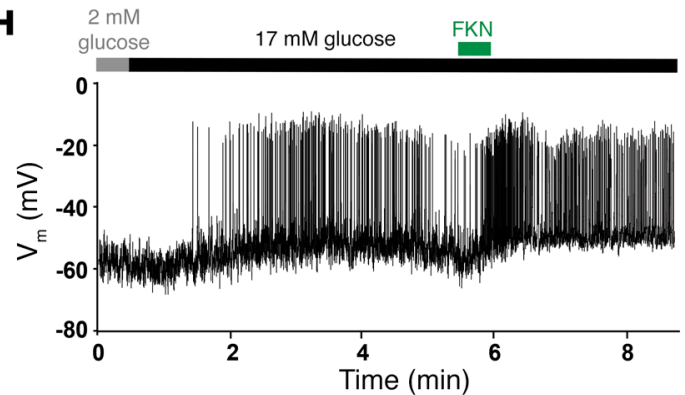

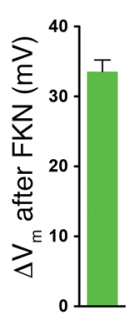
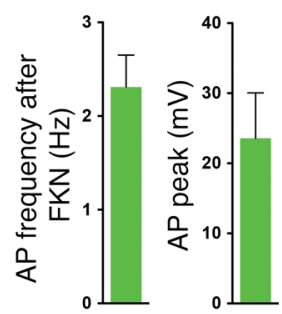

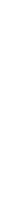



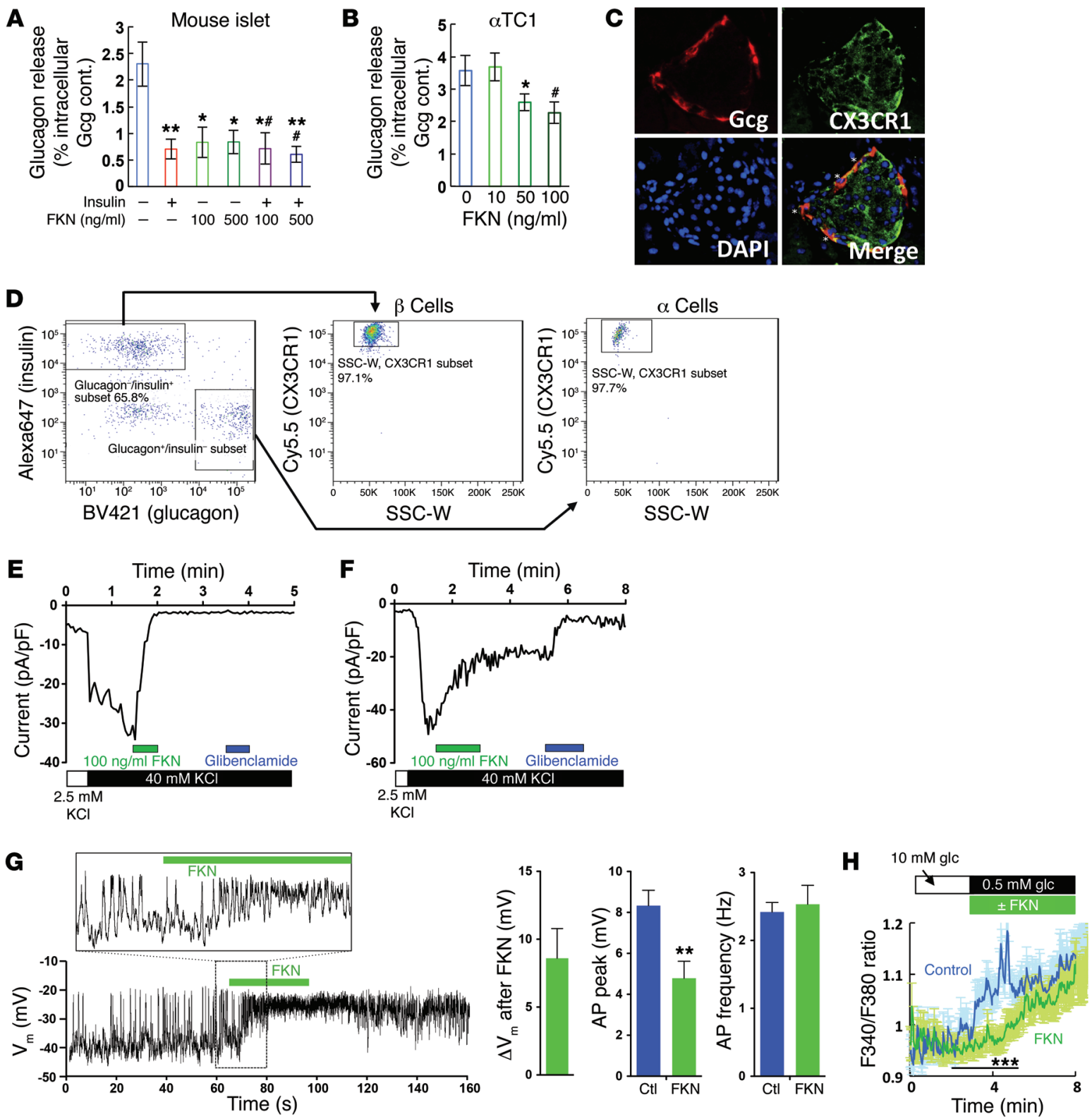

Figure 5. Electrophysiology studies in $\alpha$ cells. (A) Glucagon secretion in primary mouse islets. Islets were incubated in $1 \mathrm{mM}$ glucose medium for 16 hours and washed. Islet glucagon (Gcg) release was measured after incubation with insulin ( $100 \mathrm{nM}$ ) or FKN (100 or $500 \mathrm{ng} / \mathrm{ml})$ for 1 hour. Mean \pm SEM; $n=5$ for control and 6 for other groups. ${ }^{*} P<0.05$ vs. lane $1 ;{ }^{* *} P<0.01$ vs. lane $1 ;{ }^{*} P<0.05$ vs. lane $2 ; 1$-way ANOVA. (B) Glucagon secretion in $\alpha \mathrm{TC1}$ cells. $\alpha \mathrm{TC1}$ cells were incubated in $1 \mathrm{mM}$ glucose medium for 16 hours and washed. Glucagon release was measured after incubation of the cells with FKN for 1 hour. Mean $\pm \mathrm{SEM} ; n=3$ (lane 4 ) or 7 (lane $1-3) .{ }^{*} P<0.05$ vs. Iane $1 ;{ }^{*} P=0.051$ vs. lane 1; 1-way ANOVA. (C) IHC analysis of CX3CR1 expression in primary WT mouse islets. Images were obtained at $\times 20$ magnification. (D) Flow cytometry analysis of CX3CR 1 expression in primary $\alpha$ and $\beta$ cells in dispersed islet cells. Right lower box in the graph is for glucagon ${ }^{+}$insulin- subset. Left upper box is for the glucagon $/$insulin ${ }^{+}$subset. (E) $\mathrm{K}_{\text {ATP }}$ currents in the presence or absence of FKN $(100 \mathrm{ng} / \mathrm{ml})$ in $\alpha \mathrm{TC} 1$ cells. (F) $\mathrm{K}_{\text {ATP }}$ currents in the presence or absence of FKN $(100 \mathrm{ng} / \mathrm{ml})$ in primary $\alpha$ cells. (G) Membrane potential $\left(\mathrm{V}_{\mathrm{m}}\right)$ and $\mathrm{AP}$ firing before and after FKN $(100 \mathrm{ng} / \mathrm{ml})$ treatment in $\alpha$ TC1 cells. Cells were incubated in $0.5 \mathrm{mM}$ glucose medium, and depolarization of membrane potential $\left(\Delta \mathrm{V}_{\mathrm{m}}\right)$, average AP peak, and AP frequency upon FKN treatment were analyzed. Ctl, control (before FKN treatment). Mean $\pm \mathrm{SEM} ; n=7$. ${ }^{* *} P<0.01 ; 2$-tailed unpaired $t$ test. $(\mathbf{H})$ Intracellular $\mathrm{Ca}^{2+}$ levels in the presence $(n=47)$ or absence $(n=31)$ of FKN. Lowering extracellular glucose concentration from 10 to 0.5 $\mathrm{mM}$ triggered $\mathrm{Ca}^{2+}$ rise in $\alpha \mathrm{TC1}$ cells. ${ }^{* *} P<0.01 ; 1$-way ANOVA. See also Supplemental Figure 5.

Figure 5, E and F, FKN suppressed $\mathrm{K}_{\mathrm{ATP}}$ currents in $\alpha \mathrm{TC} 1$ and primary $\alpha$ cells, and this effect was sensitive to the U0126 MEK inhibitor (Supplemental Figure 5A). Moreover, inhibition of $\mathrm{K}_{\text {ATP }}$ activity by FKN was sufficient to depolarize membranes from $-40 \mathrm{mV}$ to -28 $\mathrm{mV}$ with a reduction of AP peak size (Figure $5 \mathrm{G}$ ). Consistent with these results, FKN suppressed the low-glucose-induced increase in intracellular $\mathrm{Ca}^{2+}$ levels (Figure $\left.5 \mathrm{H}\right)$. These effects of FKN occurred without changes in cAMP levels (Supplemental Figure 5B).

\section{Discussion}

In this study, we demonstrate that chronic administration of a long-acting form of FKN, FKN-Fc, exerts durable effects to 
improve glucose tolerance without changing body weight. This is associated with a direct effect of FKN-Fc to improve GSIS and decrease $\beta$ cell apoptosis. In addition, we found that FKN-Fc treatment led to a tissue-specific improvement in hepatic insulin sensitivity. From a mechanistic point of view, we traced this latter effect to direct actions of FKN-Fc to decrease $\alpha$ cell glucagon secretion and inhibit hepatocyte glucagon action both in vitro and in vivo. As such, these findings demonstrate that chronic longacting FKN treatment leads to improved glucose tolerance due to enhanced insulin secretion, decreased glucagon secretion, and improved hepatic insulin sensitivity. Taken together, these studies suggest the possibility that the FKN/FKN receptor axis (CX3CL1/ CX3CR1) could be a new area for antidiabetic drug discovery, which can improve both insulin secretion and insulin sensitivity.

We previously reported that $\beta$ cells express CX3CR1 and FKN increases insulin secretion by an ERK-dependent increase of the intracellular $\mathrm{Ca}^{2+}$ level (27). However, the molecular mechanisms of how FKN stimulates intracellular $\mathrm{Ca}^{2+}$ level were unknown. Since oxygen consumption rate in islet cells was not changed by FKN treatment, or deletion of CX3CR1, and mitochondrial content and morphology was normal in CX3CR1-KO mouse islets (27), it is possible that the FKN/CX3CR1 system enhances GSIS and intracellular $\mathrm{Ca}^{2+}$ levels by modulating the electrical activity of $\beta$ cells. Consistent with this, we found that FKN treatment did change cellular ATP levels, the ATP/ADP ratio, and oxygen consumption rates in both low- and high-glucose conditions. To further address this question, we used electrophysiological studies to measure $\mathrm{K}_{\mathrm{ATP}}$ channel and VDCC activity directly in $\beta$ cells in the presence and absence of FKN. These experiments revealed that FKN inhibits $\mathrm{K}_{\text {ATP }}$ channel activity through an ERK-dependent and ATP-independent mechanism, without effects on VDCC activity. It is known that glucose triggers the insulin secretory pathway by increasing the $\beta$ cell ATP/ADP ratio and inhibiting $\mathrm{K}_{\text {ATP }}$ channel activity $(21,32)$. This leads to membrane depolarization with opening of VDCCs, leading to a rise in intracellular $\mathrm{Ca}^{2+}$ levels and exocytosis of insulin secretory granules (21). Notably, in low-glucose conditions, FKN treatment-triggered AP firing did not lead to a substantial increase in insulin secretion. This is consistent with the literature that shows that increased intracellular $\mathrm{Ca}^{2+}$ levels induced by voltage-gated L-type $\mathrm{Ca}^{2+}$ channel (VDCC) activator treatment, $\mathrm{K}^{+}$overload, $\mathrm{K}_{\mathrm{ATP}}$ channel inhibitor treatment, or arginine treatment are not sufficient to stimulate insulin secretion, if not accompanied by increased $\beta$ cell metabolism or other events normally induced by glucose (33-36). In T2DM, it has been suggested that decreased $\beta$ cell glucose responsiveness is associated with lower mitochondrial ATP production capacity, leading to incomplete inhibition of $\mathrm{K}_{\mathrm{ATP}}$ channel activity (21, 23, $32,37,38)$. Therefore, it is reasonable to suggest that the action of FKN to inhibit basal $\mathrm{K}_{\mathrm{ATP}}$ channel conductance may compensate for lower mitochondrial ATP production in type 2 diabetic $\beta$ cells and, thus, enhance GSIS.

Similarly to $\beta$ cells, $\alpha$ cells also have an intrinsic glucosesensing mechanism through $\mathrm{K}_{\text {ATP }}$ channel regulation. It has been suggested that a progressive and time-dependent increase in $\alpha$ cell $\mathrm{K}^{+}$channel activity may be associated with the lack of glucagon suppression by glucose in T2DM $(21,22)$. Indeed, inhibition of $\mathrm{K}_{\text {ATP }}$ channel activity leads to partial restoration of glucose- dependent suppression of $\alpha$ cell glucagon release in islets from T2DM subjects (22). Interestingly, flow cytometry analyses revealed that CX3CR1 is detected in more than $90 \%$ of primary mouse $\alpha$ cells, and incubation of $\alpha \mathrm{TC} 1$ cells with FKN inhibited low-glucose-induced glucagon release. Together, these results suggest that FKN can suppress glucagon release in a cell-autonomous mechanism. This is consistent with our findings that FKN-Fc treatment reduces circulating plasma glucagon levels. However, it is possible that the FKN effect to inhibit glucagon secretion is indirect. For example, FKN can increase insulin secretion, and insulin can suppress $\alpha$ cell glucagon release $(27,39,40)$. Indeed, while we found that over $97 \%$ of $\alpha$ cells expressed CX3CR1, some years ago, Thorel et al. reported that $98 \% \alpha$ cell depletion does not affect glucose tolerance, suggesting that only $2 \%$ of $\alpha$ cells may be sufficient to maintain adequate glucagon levels (41). While the effects of FKN were ERK-dependent, we do not know whether the role of ERK is direct or indirect, or whether this involves a specific $\mathrm{K}_{\mathrm{ATP}}$ channel phosphorylation event.

An important component of $\beta$ cell dysfunction in T2DM is decreased overall $\beta$ cell mass, which advances in the later stage of the disease (42). While increased $\beta$ cell apoptosis may be responsible for the majority of decreased $\beta$ cell mass in advanced T2DM patients $(42,43)$, recently it has been suggested that an additional mechanism may exist. Thus, accumulation of dedifferentiated/ immature $\beta$ cells, which express markers of both $\alpha$ and $\beta$ cells, has been reported in mouse models of diabetes as well as in human T2DM islets $(4,32,43-45)$. While the origin of these dedifferentiated/immature $\beta$ cells is still controversial in humans $(32,43)$, it is plausible that strategies to suppress $\beta$ cell apoptosis and/or increase $\beta$ cell differentiation/maturation would be effective at improving $\beta$ cell function. Interestingly, chronic FKN-Fc administration enhanced GSIS and decreased $\beta$ cell apoptosis. This was accompanied by increased $\beta$ cell mass and the expression of the genes involved in $\beta$ cell differentiation and function. It should be noted that chronic FKN-Fc administration began at 10 weeks of HFD, at which point $\beta$ cell dysfunction and dedifferentiation already exist $(46,47)$.

Our findings that long-term FKN treatment leads to decreased insulin resistance due to a tissue-specific effect to improve hepatic insulin sensitivity represent an additional component of the antidiabetic effects of FKN. Glucagon is a key counterregulatory hormone to insulin, and stimulates CAMP production with activation of the protein kinase A (PKA) pathway, ultimately leading to increased endogenous glucose production. Postprandial increases in blood glucose and insulin levels normally suppress $\alpha$ cell glucagon secretion and inhibit hepatic glucagon action. In T2DM, a lack of glucagon suppression leads to elevated levels of basal and postprandial glucagon, contributing to hyperglycemia (48-52). There are many studies showing the efficacy of inhibitory glucagon receptor antibodies to improve glucose tolerance in preclinical models and in some clinical studies $(12,53-55)$. Thus, the concept of targeting glucagon action to achieve hepatic insulin sensitivity and glucose lowering is well accepted (14), even though current methods of glucagon receptor inhibition may have unwanted side effects (56). Using hyperinsulinemic-euglycemic clamp studies, we determined that chronic FKN-Fc treatment specifically improves hepatic 
insulin sensitivity in HFD/obese mice. We also show that this effect was direct and cell-autonomous by finding that FKN treatment of primary mouse hepatocytes directly inhibits glucagon action with a corresponding decrease in cAMP levels and PKA activity. Furthermore, all of these effects were pertussis toxindependent, but not sensitive to MEK inhibitors, demonstrating that the FKN/CX3CR1 pathway in hepatocytes signals through a classical $G_{\alpha i}$-coupled pathway to inhibit adenylate cyclase activity. It is interesting to note that FKN treatment decreased hepatic glucagon action without causing a compensatory increase in plasma glucagon levels or $\alpha$ cell hyperplasia, as occurs in glucagon receptor-KO mice or after chronic treatment with a glucagon receptor antagonist $(55,57)$. Taken together with previously reported effects of the FKN/CX3CR1 system to improve hepatic fibrosis $(58,59)$, our results support the idea that chronic FKN administration can improve glucose tolerance and hepatic function through direct hepatic actions.

Sindhu et al. have reported a $45 \%$ increase in circulating soluble FKN levels in type 2 diabetic patients (60). However, other reports have found no significant increase (61). It should be noted that, to the extent that circulating FKN levels might be elevated in type 2 diabetics, this might raise the possibility of $\mathrm{FKN}$ resistance. Of course, the issue of FKN sensitivity or resistance in human subjects is entirely unknown and will await clinical trials for an answer.

Here, we report that chronic FKN-Fc administration exerts durable effects to improve glucose tolerance by enhancing insulin secretion and suppressing glucagon secretion. In addition, FKN-Fc administration leads to improved hepatic insulin sensitivity through direct hepatocyte-selective effects to inhibit glucagon action. These results raise the possibility that the FKN/CX3CR1 system could be targeted for antidiabetic drug discovery efforts.

\section{Methods}

Animals and treatments. Seven-week-old male WT C57BL/6J, Cx3cr1 ${ }^{\text {sfp/sffe }}$ knockin mice and B6.Cg-Tg(Ins1-EGFP)1Hara/J mice were obtained from The Jackson Laboratory and fed normal chow diet (NCD) until they were subjected to 60\% HFD (Research Diets Inc.). For acute and chronic FKN-Fc injection studies, mice were randomly separated into 2 groups and subjected to vehicle or FKN-Fc administration. When 10 $\mathrm{mg} / \mathrm{kg}$ FKN-Fc was injected i.p. into normal mice, the FKN-Fc level peaked at $598.9 \mu \mathrm{M}$ in 4 hours and decreased to $31.6 \mu \mathrm{M}$ in 24 hours. Since the dose of $100 \mathrm{ng} / \mathrm{ml}$ native FKN (chemokine domain) used in in vitro studies corresponds to $10.5 \mu \mathrm{M}, 10 \mathrm{mg} / \mathrm{kg}$ dose was used in the every-other-day injection protocol in NCD mice. We used $30 \mathrm{mg} /$ $\mathrm{kg}$ in HFD mice to assure maximal effects. Intraperitoneal glucose and insulin tolerance tests were performed as described previously $(62,63)$. Mouse clamp experiments were performed as described previously $(63,64)$. During the clamps, insulin was infused at a constant rate of $8.0 \mathrm{mU} / \mathrm{kg} / \mathrm{min}$.

For testing acute effects of FKN-Fc administration, mice were fasted for 6 hours, i.p. injected with glucose $(1 \mathrm{~g} / \mathrm{kg})$ alone or glucose $(1 \mathrm{~g} /$ $\mathrm{kg})+\mathrm{FKN}-\mathrm{Fc}(10 \mathrm{mg} / \mathrm{kg})$ and blood glucose and plasma insulin levels were measured. For chronic FKN-Fc treatment studies, WT or CX3CR1 KO mice were fed HFD for 10 weeks and then i.p. injected with $30 \mathrm{mg} /$ $\mathrm{kg}$ FKN-Fc every other day for an additional 8 weeks. 6 hours before measuring glucose tolerance and serum insulin levels, mice were given a final FKN-Fc administration and the food was withdrawn.
Plasma protein measurements. Plasma insulin (ALPCO) and glucagon (Mercodia) levels were measured by ELISA. Plasma FKN-Fc levels were measured by a sandwich ELISA method.

Immunohistochemistry and relative $\beta$ cell mass calculation. Immunohistochemistry analyses of mouse pancreatic tissues were performed as described previously (27). Anti-insulin antibody was purchased from DAKO (catalog IS200). Anti-active caspase-3 antibody was purchased from Cell Signaling (catalog 9579; clone D3E9). AntiCX3CR1 antibody was purchased from Torrey Pines Biolabs Inc. (catalog TP501). Anti-glucagon (catalog ab10988) antibody was purchased from Abcam. Islet mass was calculated as relative percentage of $\beta$ cell mass per body weight $=$ [pancreas weight $\times$ (insulin-positive $\beta$ cell area/total pancreatic section area $)^{3 / 2}$ ] / body weight $\times 100$.

Flow cytometry analysis of CX3CR1 expression in primary islet cells. Isolated islets were dispersed by pipetting 20 times in $0.25 \%$ trypsin/ EDTA diluted in Eagle minimal essential medium (MEM) (catalog 10-010-CV; Life Technologies) without calcium or magnesium, then washed in MEM. The approximate yield was about 100,000 cells per 100 islets. Five hundred thousand cells were then incubated with 1:1,000 dilution of LIVE/DEAD Aqua (catalog L34957; Invitrogen) and 1:100 dilution of anti-CD16/32 antibody (catalog 14-0161-82; eBioscience) for 30 minutes on ice in PBS, washed twice, and incubated with anti-CX3CR1-PerCP/Cy5.5 antibody in PBS containing 2\% FBS (catalog 149009; Biolegend). Cells were fixed overnight in BD stabilizing fixative (catalog 338036; BD Biosciences), washed twice, and permeabilized using an intracellular staining kit (catalog 00-5521-00; eBioscience). Cells were then incubated with the following antibodies diluted in PBS containing 2\% FBS: anti-insulin-Alexa Fluor 647 (catalog 565689; BD Biosciences) and anti-glucagon-BV421 (catalog 565891; BD Biosciences). After washing, cells were acquired on a BD Canto RUO flow cytometer. During analysis, all gates were set relative to "fluorescence minus one" controls containing all fluorochromes minus the one of interest.

Measurement of insulin and glucagon secretory activity. Primary mouse islets were isolated and static GSIS assays were performed as described previously (27). For measuring glucagon release, $\alpha \mathrm{TC} 1$ cells were incubated in $1 \mathrm{mM}$ glucose DMEM for 16 hours and washed twice with Krebs-Ringer Bicarbonate (KRB) buffer $\left(2.5 \mathrm{mM} \mathrm{CaCl} / 2 \mathrm{H}_{2} \mathrm{O}\right.$, $1.16 \mathrm{mM} \mathrm{MgSO}_{4} / 7 \mathrm{H}_{2} \mathrm{O}, 1.2 \mathrm{mM} \mathrm{KH}_{2} \mathrm{PO}_{4}, 4.7 \mathrm{mM} \mathrm{KCl}, 114 \mathrm{mM} \mathrm{NaCl}$, $25.5 \mathrm{mM} \mathrm{NaHCO}_{3}, 20 \mathrm{mM}$ HEPES/Na-HEPES, and 0.2\% BSA). Glucagon release was measured after incubation of the cells in KRB buffer supplemented by $1 \mathrm{mM}$ glucose with FKN for 1 hour. $\alpha \mathrm{TC} 1$ cells were purchased from ATCC. Min6 cells were obtained and maintained as described previously (27). Absence of mycoplasma contamination was tested and confirmed in Min 6 and $\alpha \mathrm{TC} 1$ cells.

Caspase-3/7 activity and viable cell activity assays. Caspase-3/7 activity and viable cell activity were measured using an ApoLive-Glo Multiplex Assay kit (Promega).

$A D P, A T P$, and cAMP level measurement. Intracellular cAMP, ADP, and ATP levels in $\alpha \mathrm{TC} 1$ or Min 6 cells were measured using a Bridge-It cAMP assay kit (Mediomics LLC) and ADP and ATP detection assay kits (Cayman Chemical; Biovision), respectively. Briefly, for cAMP measurement, $\alpha \mathrm{TC} 1$ cells were plated in 96-well plates at a density of $5 \times 10^{4}$ cells per well. After 2 days, medium was replaced with $1 \mathrm{mM}$ glucose KRB buffer for 2 hours. The buffer was removed and replaced with the following for 1 hour: $1 \mathrm{mM}$ glucose $\mathrm{KRB}, 1 \mathrm{mM}$ glucose $\mathrm{KRB}+$ $100 \mathrm{nM}$ insulin, $1 \mathrm{mM}$ glucose $\mathrm{KRB}+10 \mathrm{ng} / \mathrm{ml}$ (or $100 \mathrm{ng} / \mathrm{ml}$ ) native 
mouse fractalkine (mFKN), 1 mM glucose KRB + 100 nM GLP-1, 25 $\mathrm{mM}$ glucose $\mathrm{KRB}$, or $1 \mathrm{mM}$ glucose $\mathrm{KRB}+10 \mathrm{ng} / \mathrm{ml}$ (or $100 \mathrm{ng} / \mathrm{ml}$ ) $\mathrm{mFKN}+100 \mathrm{ng} / \mathrm{ml}$ pertussis toxin. After the incubation period, the Bridge-It Cyclic AMP Designer Assay was used to determine intracellular cAMP levels per the manufacturer's instructions (catalog 122934; Mediomics LLC).

Primary mouse hepatocyte isolation and in vitro glucose production assay. Mice were infused through the inferior vena cava with a calcium-free HEPES-phosphate buffer ( $\mathrm{pH}$ 7.4) for 10 minutes followed by a collagenase solution (Liberase TM; Roche) for 10 minutes. The digested livers were excised, and hepatocytes were collected and washed 5 times in buffer by centrifuging at $70 \mathrm{~g}$ for 5 minutes. Cells were further purified by centrifugation $(2,400 \mathrm{~g}$ for 10 minutes) over a Percoll density gradient $(1.06 \mathrm{~g} / \mathrm{ml})$. Primary mouse hepatocytes were allowed to attach for 6 hours on collagen-coated plates in Williams' Medium E (Catalog 12551-032; Life Technologies) fortified with nonessential amino acids, GlutaMAX (catalog 35050-061; Life Technologies), antibiotics, $10 \%$ FBS, and dexamethasone (10 nM) and cultured overnight in the same medium without serum. Cultures were then washed in HEPES phosphate-salt-bicarbonate (HPSB) buffer (10 mM HEPES, 4 mM KCl, $125 \mathrm{mM} \mathrm{NaCl}, 0.85 \mathrm{mM} \mathrm{KH}_{2} \mathrm{PO}_{4}, 1.25 \mathrm{mM}$ $\mathrm{Na}_{2} \mathrm{HPO}_{4}, 1 \mathrm{mM} \mathrm{MgCl}, 1 \mathrm{mM} \mathrm{CaCl}$, and $15 \mathrm{mM} \mathrm{NaHCO}_{3}$ ) containing $0.2 \%$ free fatty acid-free BSA, and incubated in the same buffer containing FKN, insulin (10 nM), and/or glucagon (10 ng/ml) and substrates for 3 hours in a $5 \% \mathrm{CO}_{2}$ incubator. ${ }^{14} \mathrm{C}$-pyruvate $(2 \mathrm{mM}$, $0.5 \mu \mathrm{Ci}$ pyruvate per incubation) was used as substrate. Incubations were carried out in $0.5 \mathrm{ml}$ buffer in 24-well plates containing 0.25 million cells per well. At the end of incubation, the buffer solutions were transferred to $1.7-\mathrm{ml}$ microcentrifuge tubes and added with $0.25 \mathrm{ml}$ $5 \% \mathrm{ZnSO}_{4}$ and $0.25 \mathrm{ml} 0.3 \mathrm{~N} \mathrm{Ba}(\mathrm{OH})_{2}$ suspensions to each tube, followed by addition of $0.5 \mathrm{ml}$ water. After centrifugation, supernatants were transferred to a fresh set of tubes and assayed for radiolabeled glucose released into the medium by separation of radiolabeled glucose by mixed-bed ion-exchange resins, AG-501x8 resins (Bio-Rad). Two hundred milligrams of resins were added to each tube, vortexed intermittently for 15 minutes, and centrifuged, and the supernatants were transferred to scintillation vials for counting radioactivity. Cells on the plates were dissolved in $1 \mathrm{~N} \mathrm{NaOH}$ for protein estimation.

Tissue lipid content measurement. Levels of lipid contents in liver samples were measured as described previously (63).

Electrophysiology. For single-cell experiments, Min 6 or $\alpha \mathrm{TC1}$ cells were cultured on poly-L-lysine-coated coverglass chips and used 2 days after plating. Cells were transferred to culture medium containing 0.5 or $2 \mathrm{mM}$ glucose 16 hours before experiments. $\mathrm{K}_{\text {ATP }}$ channel currents in Min 6 and $\alpha \mathrm{TC} 1$ cells were recorded using the patch-clamp technique with an EPC 9 patch-clamp amplifier (HEKA Elektronik) at a sampling rate of $3.5 \mathrm{kHz}$. Patch electrodes had a resistance between 6 and $9 \mathrm{M} \Omega$ when filled with internal solution for whole-cell recording. External solutions contained the following (in $\mathrm{mM}$ ): (a) $2.5 \mathrm{mM}$ $\mathrm{KCl}$ solution: $135 \mathrm{NaCl}, 2.5 \mathrm{KCl}, 2 \mathrm{CaCl}_{2}, 1 \mathrm{MgCl}_{2}, 2 \mathrm{D}$-glucose, and 10 HEPES; and (b) $40 \mathrm{mM} \mathrm{KCl}$ solution: $105 \mathrm{NaCl}, 40 \mathrm{KCl}, 2 \mathrm{CaCl}_{2}$, $1 \mathrm{MgCl}_{2}, 2 \mathrm{D}$-glucose, and 10 HEPES. All external solutions were adjusted to $\mathrm{pH} 7.4$ with $\mathrm{NaOH}$. Internal pipette solution contained (in $\mathrm{mM}$ ): $105 \mathrm{KCl}, 10 \mathrm{HEPES}, 1 \mathrm{MgCl}_{2}, 1 \mathrm{CaCl}_{2}, 10 \mathrm{EGTA}$, and 0.6 Na-ATP, pH 7.2 adjusted with KOH. The current was expressed as current density $(\mathrm{I}, \mathrm{pA} / \mathrm{pF})$ to compensate for different cell sizes. Recordings were performed at room temperature $\left(22^{\circ} \mathrm{C}-24^{\circ} \mathrm{C}\right)$. Inhibition of $\mathrm{K}_{\text {ATP }}$ channel activity by FKN was calculated as inhibition of $\mathrm{K}_{\text {ATP }}$ current $=\left\{1-\left[\left(\mathrm{I}_{-90}-\mathrm{I}_{-40}\right)_{\mathrm{FKN}}-\left(\mathrm{I}_{-90}-\mathrm{I}_{-40}\right)_{\text {glibenclamide }}\right] /\left[\left(\mathrm{I}_{-90}-\mathrm{I}_{-40}\right)_{40 \mathrm{KCl}}-\right.\right.$ $\left.\left.\left(\mathrm{I}_{-90}-\mathrm{I}_{-40}\right)_{\text {glibenclamide }}\right]\right\} \times 100$, where $\mathrm{I}_{-90}$ and $\mathrm{I}_{-40}$ are the current density at $-90 \mathrm{mV}$ and at $-40 \mathrm{mV}$, respectively. Basal zero current level was obtained with $1 \mu \mathrm{M}$ glibenclamide. To measure $\mathrm{K}_{\mathrm{ATP}}$ activity in $\beta$ and $\alpha$ cells contained in intact primary mouse islets, the islet cell types were identified in 2 ways. Functionally, membrane currents were measured after the voltage was stepped from $-70 \mathrm{mV}$ to $0 \mathrm{mV}$ with a $\mathrm{K}^{+}$-containing solution in the pipette along with tetraethylammonium (TEA; an inhibitor of voltage-gated $\mathrm{K}^{+}$channels) in extracellular solution. This TEA-containing extracellular solution has been suggested in previous reports (65). In these new recordings, we have observed 2 major patterns of membrane current: (a) slowly inactivating $\mathrm{Ca}^{2+}$ currents without rapidly activating or inactivating $\mathrm{Na}^{+}$currents, and (b) $\mathrm{Na}^{+}$currents followed by rapidly inactivating TEA-resistant $\mathrm{K}^{+}$ currents. These 2 different patterns have previously been reported as characteristic of $\beta$ and $\alpha$ cells, respectively. To confirm that this functional identification method using current patterns for $\alpha$ and $\beta$ cells in intact islets is accurate, we prepared primary islets from transgenic mice expressing GFP under the control of the insulin 1 promoter [B6. $\mathrm{Cg}-\mathrm{Tg}$ (Ins1-EGFP)1Hara/J]. We tested whether each of the unique patterns of electrical activity for $\beta$ and $\alpha$ cells matches with GFP positivity or negativity of the islet surface cells. As seen in Supplemental Figure 4, A and B, all of the $\mathrm{GFP}^{+}$cells we tested exhibited slowly inactivating $\mathrm{Ca}^{2+}$ currents, without rapidly activating or inactivating $\mathrm{Na}^{+}$currents, consistent with previous reports (65). On the other hand, most of the $\mathrm{GFP}^{-}$surface islet cells exhibited $\mathrm{Na}^{+}$currents, followed by rapidly inactivating TEA-resistant $\mathrm{K}^{+}$currents. Therefore, cells exhibiting the slowly inactivating $\mathrm{Ca}^{2+}$ currents without any $\mathrm{Na}^{+}$ currents were considered as $\beta$ cells, while the cells exhibiting $\mathrm{Na}^{+}$ currents followed by transient TEA-resistant $\mathrm{K}^{+}$currents were considered as $\alpha$ cells. The external solution for identifying islet cell types contained (in mM): $120 \mathrm{NaCl}, 2.5 \mathrm{KCl}, 10 \mathrm{CaCl}_{2}, 1 \mathrm{MgCl}_{2}, 2 \mathrm{D}$-glucose, 10 HEPES, 10 tetraethylammonium chloride (TEA-Cl), pH 7.4 adjusted with $\mathrm{NaOH}$. VDCC activity in Min6 cells was recorded using the whole-cell patch-clamp technique with an EPC 9 patch-clamp amplifier (HEKA Elektronik). $\mathrm{Ca}^{2+}$ channels were activated by voltage steps from $-80 \mathrm{mV}$ to various membrane potentials $(-70$ to +20 $\mathrm{mV}$ ) with $10 \mathrm{mV}$ increments with an extracellular solution containing $10 \mathrm{mM} \mathrm{CaCl}_{2}$. For time course measurements of VDCC activity, the external solution contained (in $\mathrm{mM}$ ): $130 \mathrm{NaCl}, 2.5 \mathrm{KCl}, 2 \mathrm{CaCl}_{2}$, $1 \mathrm{MgCl}_{2}, 10$ TEA-Cl, 10 HEPES, and 10 D-glucose, pH 7.2 adjusted with $\mathrm{NaOH}$. The $2 \mathrm{mM} \mathrm{CaCl}_{2}$ was replaced by $10 \mathrm{mM} \mathrm{CaCl}_{2}$ to enhance $\mathrm{Ca}^{2+}$ channel currents. The internal pipette solution contained (in $\mathrm{mM}$ ): 130 Cs-glutamate, $10 \mathrm{CsCl}, 10 \mathrm{HEPES}, 1 \mathrm{MgCl}_{2}$, 3 EGTA, 3 MgATP, and 0.3 NaGTP, pH 7.2 adjusted with CsOH. Membrane potential in Min 6 and $\alpha \mathrm{TC} 1$ cells was recorded in the current clamp mode of perforated whole-cell configuration in an internal solution containing (in $\mathrm{mM}$ ): $76 \mathrm{~K}_{2} \mathrm{SO}_{4}, 10 \mathrm{KCl}, 10 \mathrm{NaCl}, 1 \mathrm{MgCl}_{2}$, 5 HEPES, and $0.25 \mathrm{mg} / \mathrm{ml}$ amphotericin B, pH 7.35 adjusted with $\mathrm{KOH}$. Extracellular solutions consisted of (in $\mathrm{mM}$ ): (a) $2 \mathrm{mM}$ glucose external solution for Min 6 cells: $135 \mathrm{NaCl}, 2.5 \mathrm{KCl}, 2 \mathrm{CaCl}_{2}, 1 \mathrm{MgCl}_{2}$, $2 \mathrm{D}$-glucose, and 10 HEPES; and (b) $0.5 \mathrm{mM}$ glucose external solution for $\alpha \mathrm{TC} 1$ cells: $140 \mathrm{NaCl}, 3.6 \mathrm{KCl}, 1.5 \mathrm{CaCl}_{2}, 0.5 \mathrm{MgSO}_{4}, 0.5 \mathrm{NaH}_{2} \mathrm{PO}_{4}$, $5 \mathrm{NaHCO}_{3}, 0.5 \mathrm{D}$-glucose, and 10 HEPES, pH 7.4 adjusted with $\mathrm{NaOH}$. The external solutions were changed by a local solution perfusion system that maintains the temperature of perfusates at $35^{\circ} \mathrm{C}-37^{\circ} \mathrm{C}(66)$. 
The recordings were semiautomatically analyzed using a macro written in Igor (WaveMetrics). For $\Delta \mathrm{V}_{\mathrm{m}}$ calculation in Min6 cells, average $\mathrm{V}_{\mathrm{m}}$ for 30 seconds right before high glucose challenge was subtracted from the average $\mathrm{V}_{\mathrm{m}}$ during 1 minute starting 1 minute after first $\mathrm{AP}$ spike or 30 seconds after FKN application. Averages of AP frequency and peak size were calculated for the same 1 minute period of time or 30 seconds after FKN application.

Fluorescence measurements of intracellular $\mathrm{Ca}^{2+}$. To measure $\left[\mathrm{Ca}^{2+}\right]_{i}$ in single cells, $\alpha \mathrm{TC} 1$ cells were loaded with $4 \mu \mathrm{M} \mathrm{Ca}^{2+}$-sensitive Fura$2 \mathrm{AM}$ for 30 minutes in the presence of $0.01 \%$ pluronic F-127 and $100 \mu \mathrm{M}$ sulfinpyrazone. Fura-2 dye was excited at 340 and $380 \mathrm{~nm}$ using a Polychrome IV (TILL Photonics, FEI Life Sciences), and the emission fluorescence was recorded at greater than $470 \mathrm{~nm}$ every 2 seconds using an EMCCD camera (Photometrics Technology) in an inverted Nikon TE2000 microscope equipped with a $\times 20$ objective lens. A cell-free region was used for background fluorescence correction. The external solutions contained the following (in $\mathrm{mM}$ ): $10 \mathrm{mM}$ glucose external solution: $135 \mathrm{NaCl}, 3.6 \mathrm{KCl}, 1.5 \mathrm{CaCl}_{2}, 0.5 \mathrm{MgSO}_{4}, 0.5$ $\mathrm{NaH}_{2} \mathrm{PO}_{4}, 5 \mathrm{NaHCO}_{3}, 10$ D-glucose, and 10 HEPES, pH 7.4 adjusted with $\mathrm{NaOH}$; for $0.5 \mathrm{mM}$ glucose external solution, $140 \mathrm{mM} \mathrm{NaCl}$ was used, instead of $135 \mathrm{mM}$. The $\mathrm{Ca}^{2+}$ measurements were performed similarly to current recordings (66).

Relative apoptotic activity assays in primary mouse islet cells. Primary mouse islets were incubated with trypsin solution, and the dispersed islet cells were plated. After overnight incubation for adhesion, cells were washed and incubated in low-glucose $(2.8 \mathrm{mM})$ or high-glucose $(16.7 \mathrm{mM})$ DMEM supplemented with $0.2 \%$ free fatty acid-free BSA or $400 \mu \mathrm{M}$ palmitate-conjugated BSA in the presence or absence of FKN-Fc treatment for 48 hours. Relative apoptotic activity was calculated by normalization of caspase-3/7 activity by viable cell activity in each well.

Oxygen consumption. Min6 cells were plated at 20,000 per well in XF96 plates for 48 hours. Culture medium was changed to lowerglucose $(2 \mathrm{mM})$ medium the night prior to the experiment. Two hours before the assay, the medium was changed to $120 \mathrm{mM} \mathrm{NaCl}, 3.5 \mathrm{mM}$ $\mathrm{KCl}, 2.3 \mathrm{mM} \mathrm{CaCl}_{2}, 0.04 \mathrm{mM} \mathrm{KH}_{2} \mathrm{PO}_{4}, 1 \mathrm{mM} \mathrm{MgCl}_{2}, 0.1 \% \mathrm{BSA}, 5 \mathrm{mM}$ HEPES ( $\mathrm{pH} 7.4$ at $37^{\circ} \mathrm{C}$ ), and $0.25 \mathrm{mM}$ glucose. Successive additions from the ports were $16.45 \mathrm{mM}$ glucose, $2 \mu \mathrm{M}$ oligomycin, $1 \mathrm{mM}$ FCCP, and then $0.25 \mu \mathrm{M}$ rotenone plus $1 \mu \mathrm{M}$ antimycin $\mathrm{A}$.

Statistics. Statistical methods were not used to predetermine necessary sample size, but sample sizes were chosen based on estimates from pilot experiments and previously published results such that appropriate statistical tests could yield significant results. Statistical analyses used in the data presented are justified and described in all legends. Parametric tests were used that assume normal distribution, which we showed to be the case when data were plotted as frequencies. Variances were tested by Levene's test for homogeneity of variance, and variances in the data were not significantly different. Experiments were not performed in a blinded fashion. The results are shown as means \pm SEM. All statistical analysis was performed by 2-tailed Student's $t$ test or ANOVA, unless indicated; $P$ less than 0.05 was considered significant. A representative figure for each experiment is presented without combining of data from different batch experiments, unless indicated in the figure legend.

Study approval. All animal procedures were performed in accordance with an IACUC-approved protocol and the research guidelines for the use of laboratory animals of the University of California, San Diego.

\section{Author contributions}

MR performed and analyzed in vivo mouse studies including glucose and insulin tolerance tests, tissue immunohistochemistry experiments, ELISA analyses of plasma hormones, ex vivo islet experiments, and in vitro Min 6 and $\alpha \mathrm{TC} 1$ cell experiments. JBS performed patch clamp experiments and intracellular $\mathrm{Ca}^{2+}$ measurements. GKB performed ex vivo primary hepatocyte experiments and tissue lipid content measurements. PL performed mouse clamp experiments. JW, HC, and AP supported in vivo mouse experiments. AM measured oxygen consumption. SP and JB produced and tested activity of the recombinant FKN-Fc protein. DB and AF performed in vivo pharmacokinetics studies. DSK supported analyses and interpretation of patch clamp experiments. SRJ performed and supported patch clamp experiments. MW, RDJ, and CJL supported design of the study and analysis of the data. JMO and YSL designed the study, supervised the project, analyzed and interpreted the data, and wrote the paper. All authors discussed the results and commented on the manuscript.

\section{Acknowledgments}

This study was funded by the US National Institute of Diabetes and Digestive and Kidney Diseases (DK074868, DK063491, and DK101395), a fellowship from the American Heart Association (to MR), the TJ Park Science fellowship of POSCO TJ Park Foundation, and a grant from Takeda California Inc.

Address correspondence to: Yun Sok Lee, Stein Clinical Research Building, Room 231, 9500 Gilman Drive, MC\# 0673, La Jolla, California 92093, USA. Phone: 858.822.6641; Email: yunsoklee@ ucsd.edu. Or to: Jerrold Olefsky, Stein Clinical Research Building, Room 227, 9500 Gilman Drive, La Jolla, California 92093, USA. Phone: 858.534.6651; Email: jolefsky@ucsd.edu.
1. Olefsky JM, Glass CK. Macrophages, inflammation, and insulin resistance. Annu Rev Physiol. 2010;72:219-246.

2. Weir GC, Bonner-Weir S. Five stages of evolving $\beta$-cell dysfunction during progression to diabetes. Diabetes. 2004;53(suppl 3):S16-S21.

3. Cersosimo E, Triplitt C, Mandarino LJ, DeFronzo RA. Pathogenesis of type 2 diabetes mellitus. In: De Groot LJ, et al., eds. Endotext. South Dartmouth, Massachusetts, USA: MDText.com Inc.; 2015. https://www.ncbi.nlm.nih.gov/books/ NBK278943/. Accessed January 31, 2018.
4. Halban PA, et al. $\beta$-Cell failure in type 2 diabetes: postulated mechanisms and prospects for prevention and treatment. Diabetes Care. 2014;37(6):1751-1758.

5. Miller RA, Birnbaum MJ. Glucagon: acute actions on hepatic metabolism. Diabetologia. 2016;59(7):1376-1381.

6. Lee YH, Wang MY, Yu XX, Unger RH. Glucagon is the key factor in the development of diabetes. Diabetologia. 2016;59(7):1372-1375.

7. Maruyama H, Hisatomi A, Orci L, Grodsky GM, Unger RH. Insulin within islets is a physi- ologic glucagon release inhibitor. J Clin Invest. 1984;74(6):2296-2299.

8. Unger RH, Cherrington AD. Glucagonocentric restructuring of diabetes: a pathophysiologic and therapeutic makeover. JClin Invest. 2012;122(1):4-12.

9. Wang MY, et al. Glucagon receptor antibody completely suppresses type 1 diabetes phenotype without insulin by disrupting a novel diabetogenic pathway. Proc Natl Acad Sci U S A. 2015;112(8):2503-2508.

10. Raskin P, Unger RH. Hyperglucagonemia and its 
suppression. Importance in the metabolic control of diabetes. N Engl J Med. 1978;299(9):433-436.

11. Yan $\mathrm{H}$, et al. Fully human monoclonal antibodies antagonizing the glucagon receptor improve glucose homeostasis in mice and monkeys. JPharmacol Exp Ther. 2009;329(1):102-111.

12. Kelly RP, et al. Short-term administration of the glucagon receptor antagonist LY2409021 lowers blood glucose in healthy people and in those with type 2 diabetes. Diabetes Obes Metab. 2015;17(4):414-422.

13. Petersen KF, Sullivan JT. Effects of a novel glucagon receptor antagonist (Bay 27-9955) on glucagonstimulated glucose production in humans. Diabetologia. 2001;44(11):2018-2024.

14. Longuet $\mathrm{C}$, et al. Liver-specific disruption of the murine glucagon receptor produces $\alpha$-cell hyperplasia: evidence for a circulating $\alpha$-cell growth factor. Diabetes. 2013;62(4):1196-1205.

15. Brunzell JD, et al. Relationships between fasting plasma glucose levels and insulin secretion during intravenous glucose tolerance tests. J Clin Endocrinol Metab. 1976;42(2):222-229.

16. Polonsky KS. Dynamics of insulin secretion in obesity and diabetes. Int JObes Relat Metab Disord. 2000;24(suppl 2):S29-S31.

17. Ward WK, Bolgiano DC, McKnight B, Halter JB, Porte D. Diminished B cell secretory capacity in patients with noninsulin-dependent diabetes mellitus. JClin Invest. 1984;74(4):1318-1328.

18. Ohneda A, Watanabe K, Horigome K, Sakai T, Kai Y, Oikawa S. Abnormal response of pancreatic glucagon to glycemic changes in diabetes mellitus. J Clin Endocrinol Metab. 1978;46(3):504-510.

19. Unger RH, Aguilar-Parada E, Muller WA, Eisentraut AM. Studies of pancreatic $\alpha$ cell function in normal and diabetic subjects. JClin Invest. 1970;49(4):837-848.

20. Marchetti P, Ferrannini E. $\beta$-Cell mass and function in human type 2 diabetes. In: DeFronzo RA, Ferrannini E, Zimmet P, Alberti KGMM. International Textbook of Diabetes Mellitus. 4th ed. Chichester, United Kingdom: John Wiley \& Sons Ltd.; 2015.

21. Ashcroft FM, Rorsman P. K(ATP) channels and islet hormone secretion: new insights and controversies. Nat Rev Endocrinol. 2013;9(11):660-669.

22. Zhang $\mathrm{Q}$, et al. Role of KATP channels in glucoseregulated glucagon secretion and impaired counterregulation in type 2 diabetes. Cell Metab . 2013;18(6):871-882.

23. Wang Z, York NW, Nichols CG, Remedi MS. Pancreatic $\beta$ cell dedifferentiation in diabetes and redifferentiation following insulin therapy. Cell Metab. 2014;19(5):872-882.

24. Shah R, et al. Fractalkine is a novel human adipochemokine associated with type 2 diabetes. Diabetes. 2011;60(5):1512-1518.

25. Ebert T, et al. Serum levels of fractalkine are associated with markers of insulin resistance in gestational diabetes. Diabet Med. 2014;31(8):1014-1017.

26. Imai $\mathrm{T}$, et al. Identification and molecular characterization of fractalkine receptor CX3CR1, which mediates both leukocyte migration and adhesion. Cell. 1997;91(4):521-530.

27. Lee YS, et al. The fractalkine/CX3CR1 system regulates $\beta$ cell function and insulin secretion. Cell. 2013;153(2):413-425.

28. Rutti S, et al. Fractalkine (CX3CL1), a new factor protecting $\beta$-cells against TNF $\alpha$. Mol Metab. 2014;3(7):731-741.

29. Gedulin BR, et al. Exenatide (exendin-4) improves insulin sensitivity and $\beta$-cell mass in insulin-resistant obese fa/fa Zucker rats independent of glycemia and body weight. Endocrinology. 2005;146(4):2069-2076.

30. Xu E, et al. Intra-islet insulin suppresses glucagon release via GABA-GABAA receptor system. Cell Metab. 2006;3(1):47-58.

31. Cooperberg BA, Cryer PE. Insulin reciprocally regulates glucagon secretion in humans. Diabetes. 2010;59(11):2936-2940.

32. Accili $\mathrm{D}$, et al. When $\beta$-cells fail: lessons from dedifferentiation. Diabetes Obes Metab. 2016;18(suppl 1):117-122.

33. Jung SR, et al. Reduced cytochrome $\mathrm{C}$ is an essential regulator of sustained insulin secretion by pancreatic islets. J Biol Chem. 2011;286(20):17422-17434.

34. Gembal M, Detimary P, Gilon P, Gao ZY, Henquin JC. Mechanisms by which glucose can control insulin release independently from its action on adenosine triphosphate-sensitive $\mathrm{K}^{+}$channels in mouse B cells. JClin Invest. 1993;91(3):871-880.

35. Henquin JC. Regulation of insulin secretion: a matter of phase control and amplitude modulation. Diabetologia. 2009;52(5):739-751.

36. Ishiyama N, Ravier MA, Henquin JC. Dual mechanism of the potentiation by glucose of insulin secretion induced by arginine and tolbutamide in mouse islets. Am J Physiol Endocrinol Metab. 2006;290(3):E540-E549.

37. Lu H, Koshkin V, Allister EM, Gyulkhandanyan AV, Wheeler MB. Molecular and metabolic evidence for mitochondrial defects associated with beta-cell dysfunction in a mouse model of type 2 diabetes. Diabetes. 2010;59(2):448-459.

38. Doliba NM, et al. Glucokinase activation repairs defective bioenergetics of islets of Langerhans isolated from type 2 diabetics. Am J Physiol Endocrinol Metab. 2012;302(1):E87-E102.

39. Raskin P, Fujita Y, Unger RH. Effect of insulinglucose infusions on plasma glucagon levels in fasting diabetics and nondiabetics. JClin Invest. 1975;56(5):1132-1138.

40. Peacey SR, Rostami-Hodjegan A, George E, Tucker GT, Heller SR. The use of tolbutamideinduced hypoglycemia to examine the intraislet role of insulin in mediating glucagon release in normal humans. J Clin Endocrinol Metab. 1997;82(5):1458-1461.

41. Thorel F, et al. Normal glucagon signaling and $\beta$-cell function after near-total $\alpha$-cell ablation in adult mice. Diabetes. 2011;60(11):2872-2882.

42. Butler AE, Janson J, Bonner-Weir S, Ritzel R, Rizza RA, Butler PC. $\beta$-Cell deficit and increased $\beta$-cell apoptosis in humans with type 2 diabetes. Diabetes. 2003;52(1):102-110.

43. Butler AE, et al. $\beta$-Cell deficit in obese type 2 diabetes, a minor role of $\beta$-cell dedifferentiation and degranulation. J Clin Endocrinol Metab. 2016;101(2):523-532.

44. Weir GC, Aguayo-Mazzucato C, Bonner-Weir S. $\beta$-Cell dedifferentiation in diabetes is important, but what is it? Islets. 2013;5(5):233-237.

45. Cinti F, et al. Evidence of $\beta$-cell dedifferentiation in human type 2 diabetes. JClin Endocrinol Metab. 2016;101(3):1044-1054.

46. Peyot ML, et al. $\beta$-Cell failure in diet-induced obese mice stratified according to body weight gain: secretory dysfunction and altered islet lipid metabolism without steatosis or reduced $\beta$-cell mass. Diabetes. 2010;59(9):2178-2187.

47. Kim-Muller JY, et al. Aldehyde dehydrogenase 1a3 defines a subset of failing pancreatic $\beta$ cells in diabetic mice. Nat Commun. 2016;7:12631.

48. Dunning BE, Foley JE, Ahrén B. $\alpha$ Cell function in health and disease: influence of glucagon-like peptide-1. Diabetologia. 2005;48(9):1700-1713.

49. Gerich JE, et al. Normalization of fasting hyperglucagonemia and excessive glucagon responses to intravenous arginine in human diabetes mellitus by prolonged infusion of insulin. JClin Endocrinol Metab. 1975;41(06):1178-1180.

50. Baron AD, Schaeffer L, Shragg P, Kolterman OG. Role of hyperglucagonemia in maintenance of increased rates of hepatic glucose output in type II diabetics. Diabetes. 1987;36(3):274-283.

51. Gastaldelli A, et al. Influence of obesity and type 2 diabetes on gluconeogenesis and glucose output in humans: a quantitative study. Diabetes. 2000;49(8):1367-1373.

52. Aronoff SL, Bennett PH, Unger RH. Immunoreactive glucagon (IRG) responses to intravenous glucose in prediabetes and diabetes among Pima Indians and normal Caucasians. JClin Endocrinol Metab. 1977;44(5):968-972.

53. Okamoto H, et al. Glucagon receptor blockade with a human antibody normalizes blood glucose in diabetic mice and monkeys. Endocrinology. 2015;156(8):2781-2794.

54. Johnson DG, Goebel CU, Hruby VJ, Bregman MD, Trivedi D. Hyperglycemia of diabetic rats decreased by a glucagon receptor antagonist. Science. 1982;215(4536):1115-1116.

55. Kazda CM, et al. Evaluation of efficacy and safety of the glucagon receptor antagonist LY2409021 in patients with type 2 diabetes: 12- and 24-week phase 2 studies. Diabetes Care. 2016;39(7):1241-1249.

56. Guan HP, et al. Glucagon receptor antagonism induces increased cholesterol absorption. J Lipid Res. 2015;56(11):2183-2195.

57. Gelling RW, et al. Lower blood glucose, hyperglucagonemia, and pancreatic $\alpha$ cell hyperplasia in glucagon receptor knockout mice. Proc Natl Acad Sci U S A. 2003;100(3):1438-1443.

58. Karlmark KR, et al. The fractalkine receptor CX(3) CR1 protects against liver fibrosis by controlling differentiation and survival of infiltrating hepatic monocytes. Hepatology. 2010;52(5):1769-1782.

59. Aoyama T, Inokuchi S, Brenner DA, Seki E. CX3CL1-CX3CR1 interaction prevents carbon tetrachloride-induced liver inflammation and fibrosis in mice. Hepatology. 2010;52(4):1390-1400.

60. Sindhu S, et al. Increased circulatory levels of fractalkine (CX3CL1) are associated with inflammatory chemokines and cytokines in individuals with type-2 diabetes. J Diabetes Metab Disord. 2017;16:15

61. Daniele G, et al. The inflammatory status score including IL- 6 , TNF- $\alpha$, osteopontin, fractalkine, 
MCP-1 and adiponectin underlies whole-body insulin resistance and hyperglycemia in type 2 diabetes mellitus. Acta Diabetol. 2014;51(1):123-131.

62. Lee YS, et al. Adipocytokine orosomucoid integrates inflammatory and metabolic signals to preserve energy homeostasis by resolving immoderate inflammation.J Biol Chem. 2010;285(29):22174-22185.
63. Lee YS, et al. Inflammation is necessary for long-term but not short-term high-fat diet-induced insulin resistance. Diabetes. 2011;60(10):2474-2483.

64. Lee YS, et al. Increased adipocyte O2 consumption triggers HIF-1 $\alpha$, causing inflammation and insulin resistance in obesity. Cell. 2014;157(6):1339-1352.
65. Göpel S, et al. Capacitance measurements of exocytosis in mouse pancreatic $\alpha$-, $\beta$ - and $\delta$-cells within intact islets of Langerhans. JPhysiol (Lond). 2004;556(pt 3):711-726.

66. Koh DS, Chen L, Ufret-Vincenty CA, Jung SR. A fast solution switching system with temperature control for single cell measurements. J Neurosci Methods. 2011;199(1):35-42. 